ORNLTM-13717

OAK RIDGE NATIONAL LABORATORY
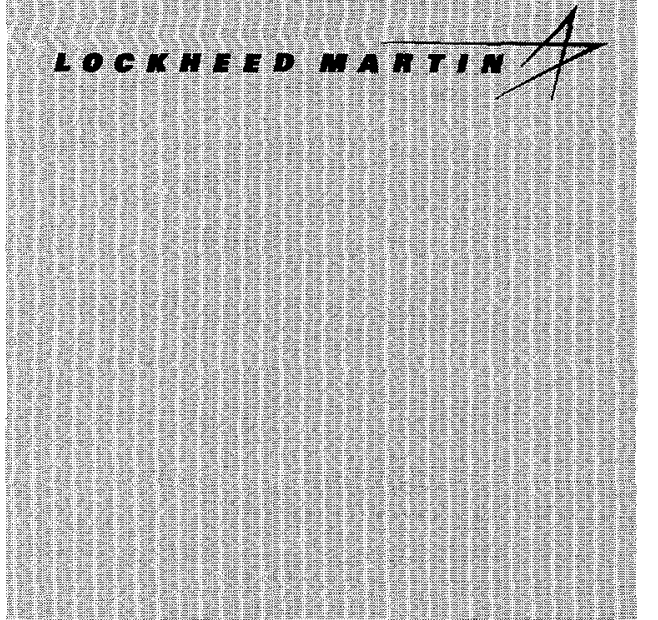

).
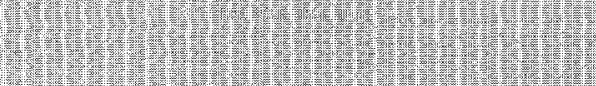

1.:.

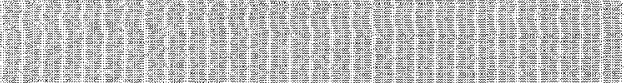

1.

(t)

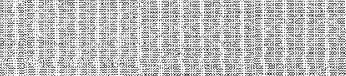

(1)

1)

(1)

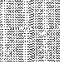

1):

(4)

1)

WWMGEO WD OPERATEO BY

LOCKHEED WARTN ENERGY RESEARCH CORPORATION FOR THE UUTED STATES

DEPARTUENT OF ENERGY

ORNL-27 (3.96)

\title{
Robotics and Automation for Flight Deck Aircraft Servicing
}

John V. Draper

François G. Pin Joel B. Chesser

\section{RECEIVED}

$$
\begin{gathered}
\text { APR } 271999 \\
\text { O STI }
\end{gathered}
$$

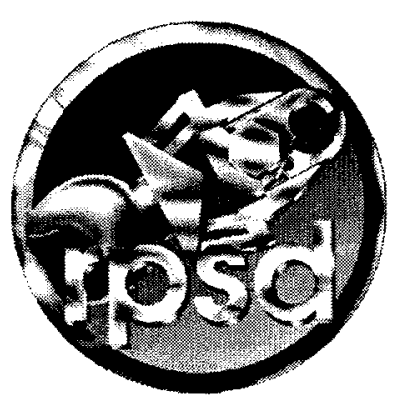


This report has been reproduced from the best available copy.

Reports are available to the public from the following source.

National Technical information Service

5285 Port Royal Road

Springfield, VA 22161

Telephone 703-605-6000 (1-800-553-6847)

TDD 703-487-4639

Fax 703-605-6900

E-mail orders $@$ ntis.fedworld.gov

Web site http://www.ntis.gov/ordering.htm

Reports are available to U.S. Department of Energy (DOE) employees, DOE contractors, Energy Technology Data Exchange (ETDE) representatives, and International Nuclear Information System (INIS) representatives from the following source.

Office of Scientific and Technical Information

P.O. Box 62

Oak Ridge, TN 37831

Telephone 423-576-8401

Fax 423-576-5728

E-mail reports@adonis.osti.gov

Web site http://www.osti.gov/products/sources.html

Reports produced after January 1, 1996, are generally available via the DOE Information Bridge.

Web site http://www.doe.gov/bridge 


\section{DISCLAIMER}

This report was prepared as an account of work sponsored by an agency of the United States Government. Neither the United States Government nor any agency thereof, nor any of their employees, make any warranty, express or implied, or assumes any legal liability or responsibility for the accuracy, completeness, or usefuiness of any information, apparatus, product, or process disclosed, or represents that its use would not infringe privately owned rights. Reference herein to any specific commercial product, process, or service by trade name, trademark, manufacturer, or otherwise does not necessarily constitute or imply its endorsement, recommendation, or favoring by the United States Government or any agency thereof. The views and opinions of authors expressed herein do not necessarily state or reflect those of the United States Government or any agency thereof. 


\section{DISCLAIMER}

Portions of this document may be illegible in electronic image products. Images are produced from the best available original document. 
ROBOTICS \& PROCESS SYSTEMS DIVISION

\title{
ROBOTICS AND AUTOMATION FOR \\ FLIGHT DECK AIRCRAFT SERVICING
}

J. V. Draper, F. G. Pin, and J. B. Chesser

Date Published: March 1999

\author{
Prepared by \\ Oak Ridge National Laboratory \\ Oak Ridge, Tennessee 37831-6285 \\ Managed by \\ LOCKHEED MARTIN ENERGY RESEARCH CORPORATION \\ for the \\ U.S. DEPARTMENT OF ENERGY \\ under contract DE-AC05-96OR22464
}





\section{TABLE OF CONTENTS}

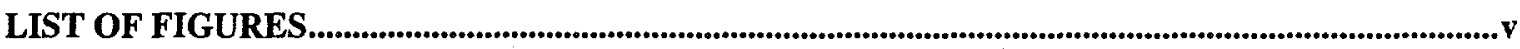

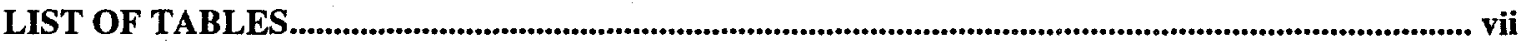

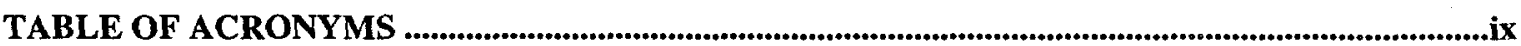

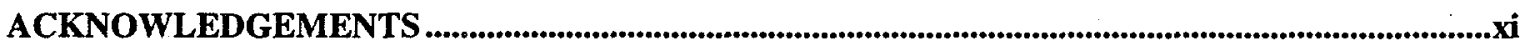

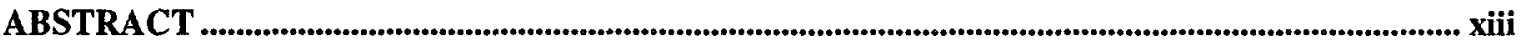

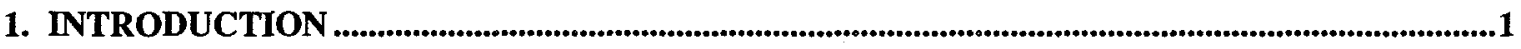

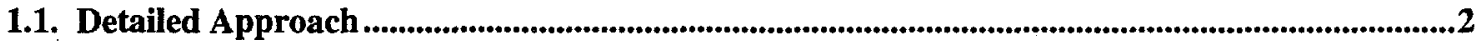

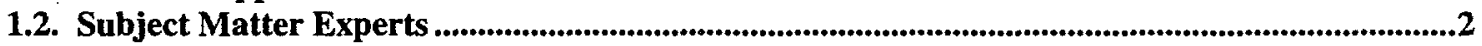

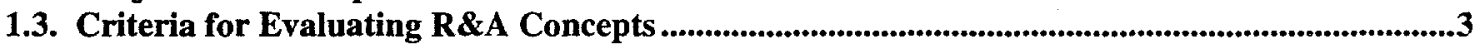

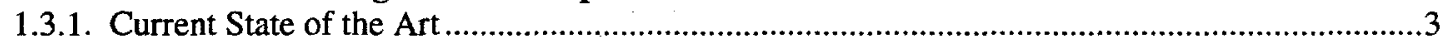

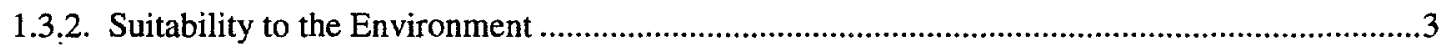

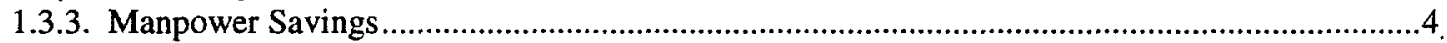

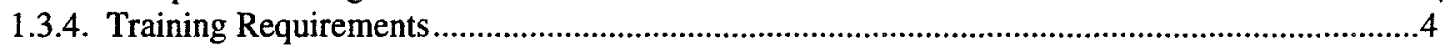

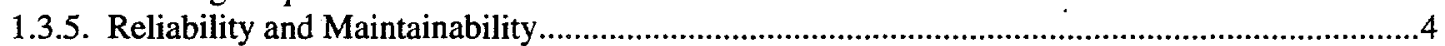

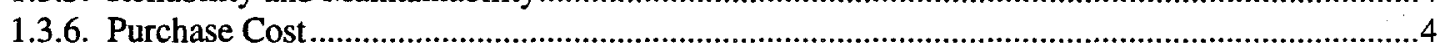

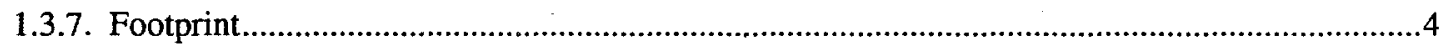

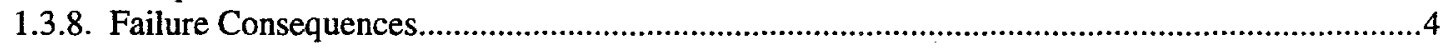

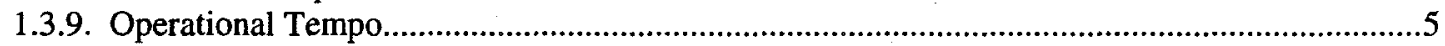

2. TASK NETWORK MODELING

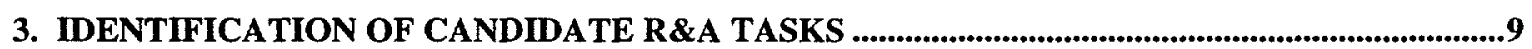

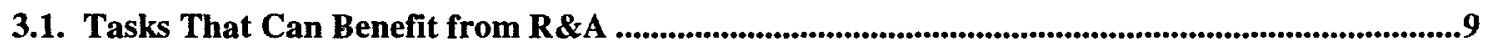

3.2. Tasks Not Likely to Benefit from R\&A .......................................................................................10

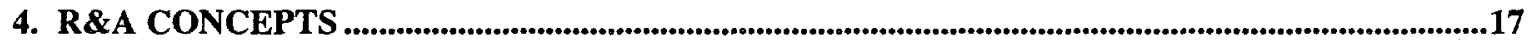

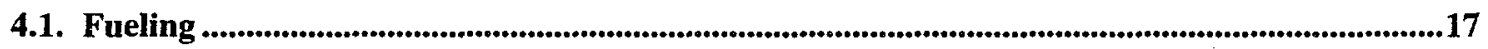

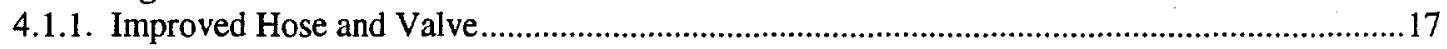

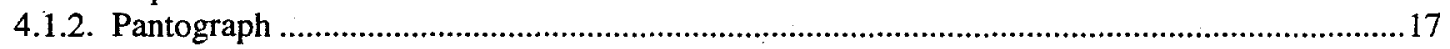

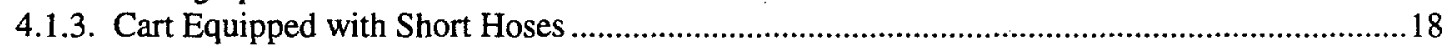

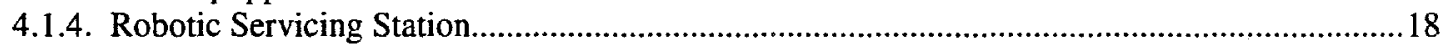

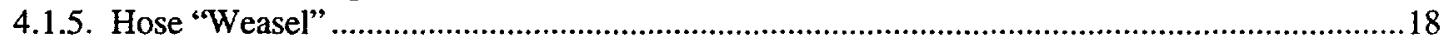

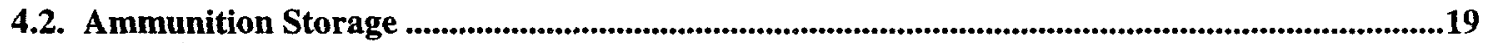

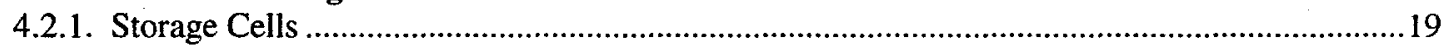

4.3. Ammunition Loading ......................................................................................................................................19

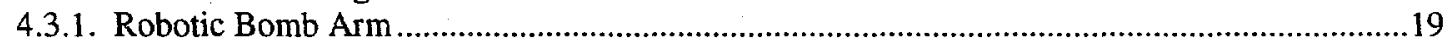

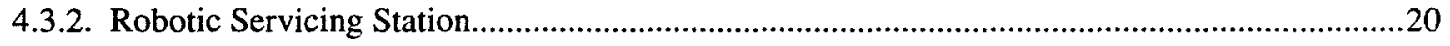

4.4. Flight Deck Ammunition Transport .................................................................................................20

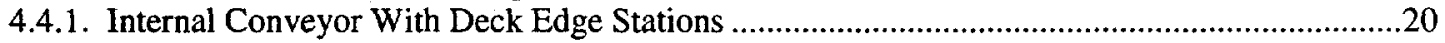

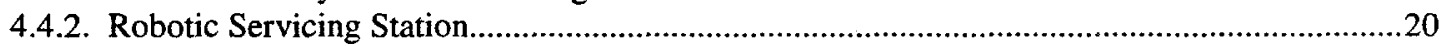

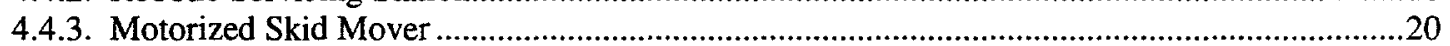

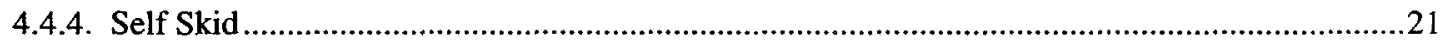

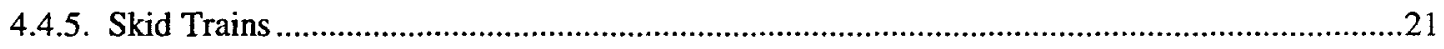

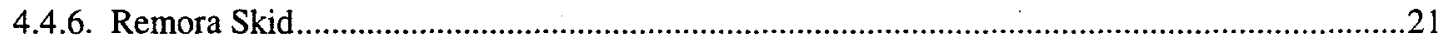

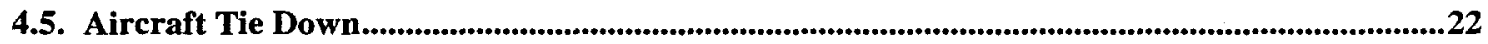

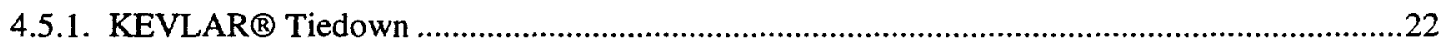




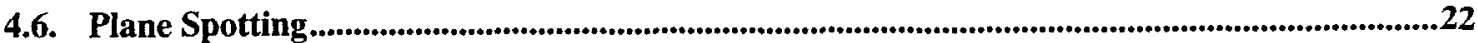

4.6.1. Omnidirectional Tractor with Integrated Towbar ........................................................22

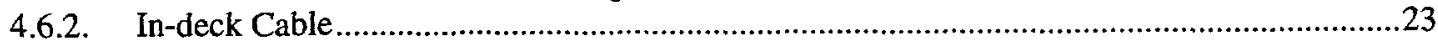

5. PERFORMANCE COMPARISONS FROM SIMULATION ............................................25

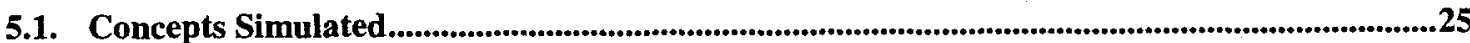

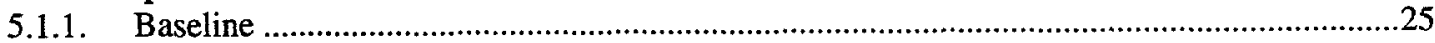

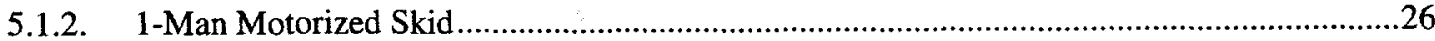

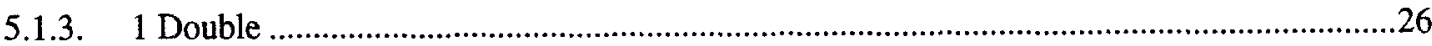

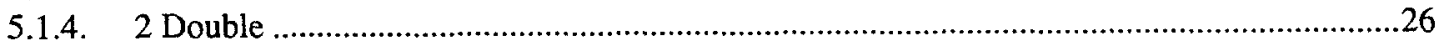

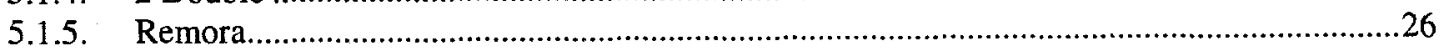

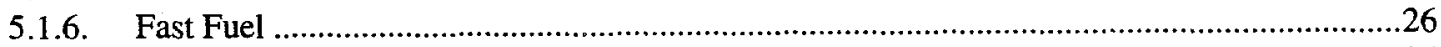

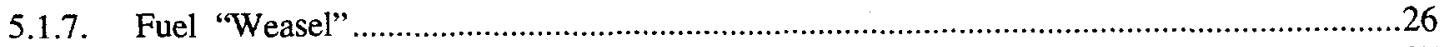

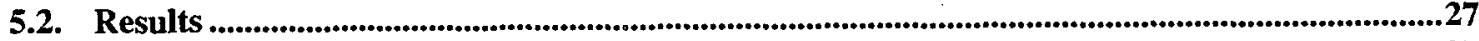

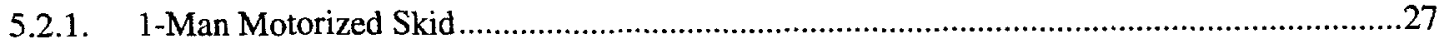

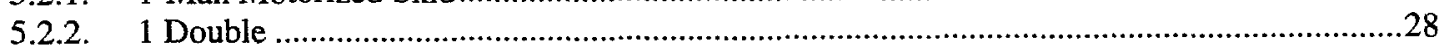

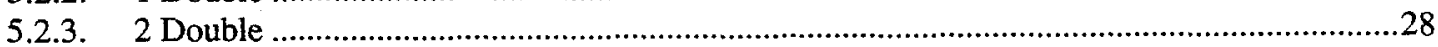

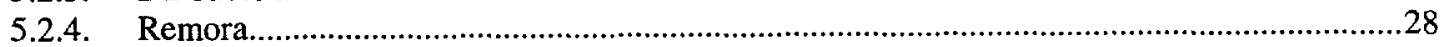

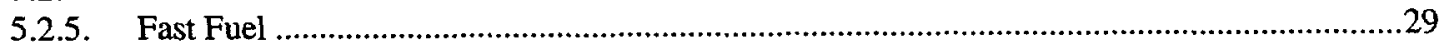

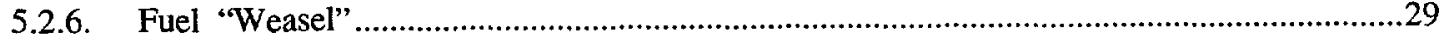

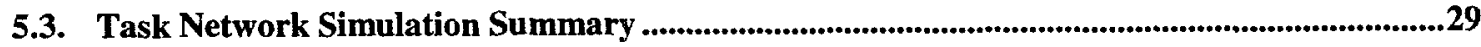

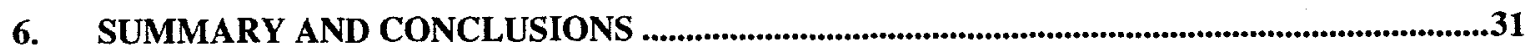

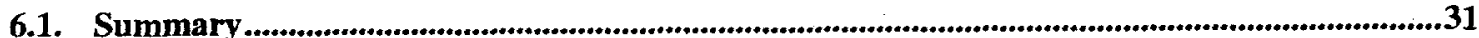

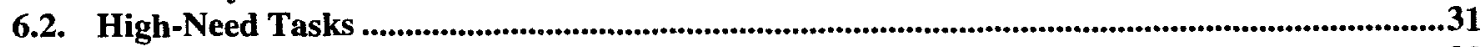

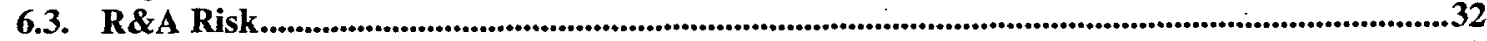

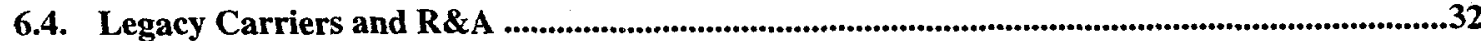

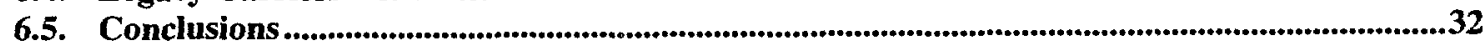

APPENDIX: TASK NETWORK MODEL EXAMPLES ..........................................................33 


\section{LIST OF FIGURES}

Figure 1. Aircraft servicing flowchart (from USN). ............................................. 33

Figure 2. Aircraft servicing high-level network.................................................. 34

Figure 3. Aircraft rearm subnetwork.............................................................. 35

Figure 4. Get munitions subnetwork models. ..................................................... 36

Figure 5. Fuel subnetwork................................................................................... 38

Figure 6. Cold refuel subnetwork (used for baseline, remora, and fast fuel models by modifying appropriate performance parameters within the network). ......... 39

Figure 7. Further fueling subnetworks. .......................................................... 40

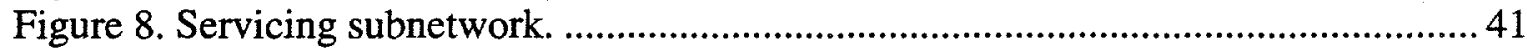





\section{LIST OF TABLES}

Table 1. Baseline Aircraft Servicing Criterion and Task Matrix .......................... 11

Table 2. Tasks Sorted by Number of Persons..................................................... 13

Table 3. Tasks Sorted by Workload ............................................................... 14

Table 4. Tasks Sorted by Operational Tempo ................................................. 15

Table 5. Results of Task Network Simulation Runs ........................................... 27 



\section{TABLE OF ACRONYMS}

CDR

LCC

LCDR

NAVAIR

NAVAIRLANT

NAVSEA

R\&A

SAINT

SME

SOA

TAT
Commander

Life-cycle costs

Lieutenant Commander

Naval Air Systems Command

Naval Air Force Atlantic Fleet

Naval Sea Systems Command

Robotics and automation

Systems analysis for integrated

networks of tasks

Subject-matter expert

State of the art

Turnaround time 



\section{ACKNOWLEDGEMENTS}

This work was performed under Interagency Agreement 2072-E123-A1 between the Oak Ridge National Laboratory and the U.S. Navy, Naval Air Warfare Center, Aircraft Division (NAWCAD), in Lakehurst, New Jersey. The project manager for NAWCAD was Mark Husni. The authors are indebted to the efforts of several subject matter experts, whose knowledge about flight deck servicing operations made this research possible. These include CDR Bob Whelan, NAVAIR; LCDR Dave Odenwelder, NAVSEA; LCDR Rich Garza, AIRLANT Norfolk; O. J. "Roby" Robinson, AIRLANT Norfolk; Dominick Riggs, NAVSEA; Rich Johnson, Newport News Shipbuilding; Jim Francis, Newport News Shipbuilding; Frank Smith, Newport News Shipbuilding; John Wander, Newport News Shipbuilding; Ira "Butch" Bowman, Newport News Shipbuilding; Billy Wright, JJMA Crystal City; Randy Salyer, Rosenblatt Crystal City; Larry Parker, Rosenblatt Crystal City; and Jim Flaherty, WBB Crystal City. 



\begin{abstract}
One of the missions of the Future Aircraft Carriers Program is to investigate methods that would improve aircraft turnaround servicing activities on carrier decks. The major objectives and criteria for evaluating alternative aircraft servicing methods are to reduce workload requirements, turnaround times (TAT), and life-cycle costs (LCC). Technologies in the field of Robotics and Automation (R\&A) have the potential to significantly contribute to these objectives.

The objective of this study was to investigate aircraft servicing functions on carrier decks which would offer the potentially most significant payoff if improved by various R\&A technologies. Improvement in this case means reducing workload, time and LCC. This objective was accomplished using a "bottom-up" formalized approach as described in the following.

All aircraft servicing activities were analyzed with respect to their current needs for workload, TAT, and LCC-related features (maintenance, support equipment, etc.) to obtain baseline values. These values served for a first ranking of each servicing activity with respect to maximum potential payoff, and for comparative analyses.

Based on the initial ranking of each servicing activity with respect to potential maximum payoffs, a set of servicing activities showing the best potential for improvement was identified. These servicing activities were then decomposed into elemental activities using a "task network" formalism. Precedence constraints, as well as other relevant constraints (operational exclusive policies, environment, variability, etc.), were folded into the Task network. Each elemental kernel of the Task network was then analyzed with respect to its perceptive, cognitive, and action attributes and needs. Implied connectivity and communication between kernels and/or between activities were expressed within the networks.

Base values for each kernel in terms of workload, time, and LCC-related data were input into the network based on information provided by the fleet experts. Each kernel attribute and needs in the networks was examined for potential performance by alternative R\&A technologies, spanning the entire spectrum of human-machine synergy, from fully manual (human performed) to fully automated. To each of these potential alternative technologies were attached various estimates, including workload, execution time, complexity, readiness to transition to deck environments, reliability, maintainability, development costs, implementation costs and implications, etc. The networks were modified to show feasible alternative paths and to include the new constraints and connectivity implications corresponding to each alternative concept/activity. Unfeasible paths were eliminated.

The study began by identifying aircraft servicing tasks that have high workload or low efficiency as possible candidates for R\&A alternatives. This approach allows future developments to be aimed at tasks that can benefit most from advanced technology, ensuring that R\&A development has a high potential payback in terms of LCC reductions. This study demonstrates that improvements to flight deck servicing, leading to LCC reductions, are possible through the application of robotics and automation, both for existing aircraft carriers and future carriers.
\end{abstract}


Task lists and task network models point to candidates for R\&A-based LCC or TAT improvements. The highest potential seems to exist in munitions handling tasks, where workload is high and in fueling.

Full automation of these tasks is probably not viable: perceptual and cognitive demands are too great for current SOA. This points to integrated sailor-robot systems that combine the perceptual and cognitive capabilities of humans with the movement capabilities of heavy-lift, dexterous robotics.

Preliminary solutions involving human-robot systems have been identified. These are examples of what may be done but require further study to validate the technical feasibility and corresponding LCC savings.

Improvements outside of the current scope also seem possible. This study had the mission of examining aircraft servicing in the context of existing aircraft carrier flight decks. More pervasive R\&A solutions involving changes in the flight and hangar decks themselves may also be possible but are outside of the scope of this study. 


\section{INTRODUCTION}

One of the missions of the Future Aircraft Carriers Program is to investigate methods that would improve aircraft turnaround servicing activities on carrier decks. The major objectives and criteria for evaluating alternative aircraft servicing methods are to reduce workload requirements, turnaround times (TAT), and life-cycle costs (LCC). Technologies in the field of Robotics and Automation (R\&A) have the potential to significantly contribute to these objectives.

The objective of this study was to investigate aircraft servicing functions on carrier decks which would offer the potentially most significant payoff if improved by various $R \& A$ technologies. Improvement in this case means reducing workload, time and LCC. This objective was accomplished using a "bottom-up" formalized approach as described in the following.

All aircraft servicing activities were analyzed with respect to their current needs for workload, TAT, and LCC-related features (maintenance, support equipment, etc.) to obtain baseline values. These values served for a first ranking of each servicing activity with respect to maximum potential payoff, and for comparative analyses in the following subtasks. The data for this first task were gathered from previous Navy studies and through interviews with fleet expert personnel.

Based on the initial ranking of each servicing activity with respect to potential maximum payoffs, a set of servicing activities showing the best potential for improvement was identified. These servicing activities were then decomposed into elemental activities along a "task network" formalism. Precedence constraints, as well as other relevant constraints (operational exclusive policies, environment, variability, etc.), were folded into the Task network. Each elemental kernel of the Task network was then analyzed with respect to its perceptive, cognitive, and action attributes and needs. Implied connectivity and communication between kernels and/or between activities were expressed within the networks.

Base values for each kernel in terms of workload, time, and LCC-related data were input into the network based on information provided by the fleet experts. Each kernel attribute and needs in the networks was examined for potential performance by alternative R\&A technologies, spanning the entire spectrum of human-machine synergy, from fully manual (human performed) to fully automated. To each of these potential alternative technologies were attached various estimates, including workload, execution time, complexity, readiness to transition to deck environments, reliability, maintainability, development costs, implementation costs and implications, etc.. The networks were modified to show feasible alternative paths and to include the new constraints and connectivity implications corresponding to each alternative concept/activity. Unfeasible paths were eliminated.

Analysis of the resulting networks and summations of the criteria-related data identified sets of preferred paths through the networks, as well as their corresponding technology components concepts. Potential for technology development payoffs were estimated from the network analysis for each preferred path (the high-ranking path with respect to expected gains in the criteria) of each servicing activity. 


\subsection{Detailed Approach}

The approach taken in this study is to examine servicing tasks through detailed task network models. This requires the following:

1. Identification of tasks and task elements: a task is an activity with a discrete beginning and end. Task elements are actions taken within the task.

2. Initial screening: tasks identified in the preceding step were evaluated in terms of their impact on workload and TAT, and on their perceptual, cognitive, and movement requirements. This permitted identification of a task subset that included those activities that may be amenable to R\&A technology. Only tasks passing through this preliminary screening were carried forward for more detailed analysis using task network modeling.

3. Development of task network models: the task network model is a flowchart for aircraft servicing. The flowchart places the tasks and task elements into a hierarchical and sequential relationship, along with decision nodes that determine how work flows through the network. Using MicroSAINT, a task network simulation software package, performance (in terms of time and workload) may be measured for a baseline servicing network and for alternative tasks and subnetworks.

4. Identification of task requirements: to understand the potential for $R \& A$, the perceptual, cognitive, and motor requirements for each task element must be identified.

5. Identification of constraints on current operations: physical and operational constraints determine, in part, the ability to develop R\&A alternatives for tasks.

6. Identification of subtasks that are likely alternatives for R\&A: using the task network models, task requirements, and task constraints, a set of subtasks comprising fruitful targets for R\&A alternatives may be identified. For example, a subtask that is quickly completed by one person is not a good candidate for R\&A. However, a subtask that takes a long time or imposes high workload is a good candidate.

7. Identification of replacements and alternatives (including R\&A): given the list of likely alternatives, it is possible to begin identifying ways in which R\&A concepts may improve aircraft servicing.

8. Evaluation of potential LCC and TAT gains (e.g., complexity vs cost, reliability vs time, etc.): returning to the task network models and to task requirements, it is possible to evaluate the potential LCC and TAT gains that can be expected from $R \& A$ alternatives.

Note that this is a first pass at a problem requiring iteration.

\subsection{Subject Matter Experts}

Several people contributed to the study by providing expert opinions on the course, timing, and workload of aircraft servicing. These included the following:

- CDR Bob Whelan, NAVAIR

- LCDR Dave Odenwelder, NAVSEA

- LCDR Rich Garza, AIRLANT Norfolk 
- O. J. "Roby" Robinson, AIRLANT Norfolk

- Dominick Riggs, NAVSEA

- Rich Johnson, Newport News Shipbuilding

- Jim Francis, Newport News Shipbuilding

- Frank Smith, Newport News Shipbuilding

- John Wander, Newport News Shipbuilding

- Ira "Butch" Bowman, Newport News Shipbuilding

- Billy Wright, JJMA Crystal City

- Randy Salyer, Rosenblatt Crystal City

- Larry Parker, Rosenblatt Crystal City

- Jim Flaherty, WBB Crystal City

The subject matter experts (SMEs) were asked to provide estimates of timing parameters for subtasks and an assessment of the number of persons engaged on each task, and to help outline the task sequence and operational procedures. These data were invaluable for constructing the task network models described later in this report.

\subsection{Criteria for Evaluating R\&A Concepts}

The following criteria are those considered in determining which flight deck tasks to automate and in evaluating various automation alternatives. The criteria are defined along with objective measures where possible. Although most of these criteria have objective measures, considering various alternatives will have an element of subjectivity because the importance of the various criteria will have to be weighed against each other. Although objective selection criteria have been identified, there will be subjectivity in the selection process because of the lack of resources to quantify the objective measures. Initially, alternatives for a task will be subjectively evaluated against the criteria using present methods as the baseline.

\subsubsection{Current State of the Art}

This criterion determines the cost to develop an automation concept. If a technology is well developed relative to the level of development required to automate a given task, development costs will be low. Conversely, if a technology is poorly developed relative to the level of development required to automate a given task, development costs will be high. The subjective measure is the length of time and cost to develop a prototype.

\subsubsection{Suitability to the Environment}

This criterion evaluates the suitability of a technology to the physical environment of the carrier deck. Equipment on a carrier deck is exposed to salt spray, temperature extremes, jet fuel, electromagnetic radiation, high intensity noise, and the pitch and roll motion of the carrier. The constraints imposed by the crowded conditions on the deck, the pace of operations, and proximity to people on the deck must also be considered. There is no single objective measure for this criterion; the determination is subjective on the 
part of relevant technical experts and requires further, more detailed study of the concepts described in this report than is possible at this stage of development.

\subsubsection{Manpower Savings}

Any carrier deck automation will be undertaken not for its own sake but for reduction in workload or manpower costs. The workload and manpower savings are critical for determining whether to automate a particular task. Manpower savings are a factor in LCC. Manpower considered includes not only the flight deck crew but also any maintenance personnel required. The objective measure is the cost of personnel required on the flight deck and the repair crew required.

\subsubsection{Training Requirements}

Training requirements include training to use and to service the equipment. Training is a factor in LCC. The measure is cost to train and develop a minimum level of proficiency, which includes training both to operate and maintain the equipment.

\subsubsection{Reliability and Maintainability}

Reliability and maintainability are critical to controlling LCC. If equipment is frequently inoperative it increases the maintenance manpower required and places additional requirements on the flight deck crew. Measures considered are mean time to failure and mean time to repair.

\subsubsection{Purchase Cost}

Purchase cost, one of the factors in LCC, is the cost to procure and install the equipment on an aircraft carrier. This cost is independent of the development cost. The objective measure is purchase cost.

\subsubsection{Footprint}

Footprint is defined as the impact the system will have on the carrier. This includes deck space requirements, utility/fuel requirements, and logistical (spare parts) requirements. The individual requirements, deck space, spare parts, and utility/fuel demands, are objective. Creating a single criterion, "footprint," however, requires subjective ranking.

\subsubsection{Failure Consequences}

Failure consequences include immediate consequences and operational consequences. Immediate consequences include personnel injury and damage to the ship or aircraft. Operational consequences are impacts to operational tempo, that is, the number of aircraft launches and recoveries. Consideration of failure consequence must also include failure frequency. A failure with significant impact may be acceptable if the failure is infrequent. The immediate consequences are a measure of system safety. There is no objective measure for failure consequence. Ranking has to be subjective. 


\subsubsection{Operational Tempo}

For a new technology to be considered it should have either a neutral or positive impact on operational tempo, that is, the number of sorties. A technology that reduces manpower requirements but has no impact on tempo would be acceptable. A technology that reduces manpower requirements but has a negative impact on tempo would be unacceptable. 



\section{TASK NETWORK MODELING}

Task network modeling is a tool for modeling systems of discrete tasks. It identifies tasks and describes the hierarchical and sequential relationships among tasks. The simulation model was developed with the MicroSAINT package, a network simulation modeling tool kit for personal computers. Network simulation is a suitable tool for modeling systems that can be decomposed into a set of discrete chronological steps or tasks. A set of tasks and pathways (which connect tasks according to their precedence) constitute the network. There are important advantages of decomposing a complex system into smaller steps: it is often easier to describe the behavior of constituent parts of a process than to describe the whole, and the performance of the whole system can be studied by varying the behavior of the constituent parts. The set of steps may be organized as an abstraction hierarchy, where the top level reveals the most general view of the operation of the network. Each box in the top level contains a subnetwork, which in turn may contain its own subnetwork, etc. Successive levels in the hierarchy show more detail of smaller parts of the entire system.

A network diagram shows the constituent parts of the simulation model. It is essentially a task block flow diagram where nodes represent activities of the system. To create a network, a task analysis is performed to identify the activities of the system. The network also shows the path or paths followed after completion of each activity. The network diagram can be implemented as a computer-based network simulation model using MicroSAINT.

Simple networks process tasks one at a time in sequential fashion. More complex networks allow multiple entities to propagate through the network in parallel fashion. Thus, it is possible for multiple tasks to be processed concurrently in such networks. Tactical and multiple branching also create the possibility that entities will follow novel paths through the network on different simulation runs.

Figures A.1 through A.8 in the Appendix present components of a task network model for flight deck aircraft servicing. These networks are based on (1) available U.S. Navy documents (e.g., Aircraft Refueling NATOPS Manual, NAVAIR 00-80T-109) and (2) interviews with SMEs. The resultant network model serves as a baseline for performance evaluation for R\&A solutions proposed later in this document.

Preliminary analysis of candidate tasks for R\&A development identified subtasks for detailed modeling (see Section 3). Detailed task subnetworks were developed for these subtasks, but not for all of the subtasks involved in servicing. 



\section{IDENTIFICATION OF CANDIDATE R\&A TASKS}

The first step in determining how R\&A may enhance flight deck aircraft servicing is identification of tasks that (1) may benefit from R\&A and (2) are feasible for state-ofthe-art R\&A technology. Manuals and SMEs helped identify aircraft servicing tasks, and tables of tasks were developed. These tasks were included in a baseline task network model, and using network simulation results and engineering judgement, evaluation of tasks was conducted considering select criteria. Criteria consisted of workload, safety, training requirements, and operational tempo (how quickly each task must be completed). Tasks were then sorted on these criteria to identify candidates for R\&A-based improvements.

\subsection{Tasks That Can Benefit from R\&A}

Table 1 presents servicing tasks with an evaluation of each in terms of the taskrelated criteria stated previously. Within the table, note for each task (1) the number of persons, (2) workload, and (3) operational tempo. It makes no sense to introduce R\&A to perform tasks that require only one person, are easy to perform, or are performed quickly. Those tasks requiring several people are the ones that will benefit from R\&A technology in terms of LCC reduction. Those tasks that impose heavy workload on the crew performing them are the ones that will benefit from R\&A in terms of reducing human errors, injuries, and fatigue (and thereby improving operational tempo in the long term). Those tasks that have the slowest operational tempo are the ones that will benefit from R\&A technology in terms of increasing the overall throughput during aircraft servicing and, therefore, reduce aircraft TAT.

From Table 1, it is possible to construct a list of tasks that are good candidates for R\&A technology and to sort that task list by priority (i.e., according to the potential benefits of new technology). Table 2 presents the task list sorted on the basis of the number of persons per aircraft required to do each subtask. Table 3 presents the same task list sorted by workload and Table 4 presents it sorted by operational tempo. Examining Tables 2 through 4 together allows identification of those subtasks that may reap the greatest benefit from $R \& A$ : any task appearing near the top of all three tables needs some help. Conversely, any task requiring only one person to perform may be rejected as a high priority for investigation toward yielding sufficient benefit from R\&A development.

From Tables 1 through 4, a set of subtasks that could benefit most from R\&A was culled:

- Loading: Get Skids

- Loading: Transport Skid

- Loading: Lift Weapon

- Fueling: Position Hose

- Fueling: Stow Hose

- Loading: Spot for Loading

- Postrecovery: Taxi to Spot

- Loading: Position Skid 
- Fueling: Monitor Fueling

- Loading: Spread Wings

- Postrecovery: Chock and Chain

The first three subtasks in the list are components of loading related to munitions transport and attachment to an aircraft. It seems, then, that a device or set of devices designed to handle aircraft rearming would be worth pursuing further.

Three other tasks in the list are related to fueling, and the most salient of these have to do with deploying fueling hoses and stowing them after use. A device or set of devices designed to perform these operations also seems worth pursuing at this time.

Other tasks in the list (spot for loading, taxi to spot, and chock and chain) are related to moving an aircraft to the proper position on the deck and securing it for servicing operations. A device or set of devices that could assist in these operations also seems worth pursuing, although perhaps at a lower priority than for loading or fueling.

\subsection{Tasks Not Likely to Benefit from R\&A}

There are tasks in the list that can be improved by non-R\&A changes. For example, the time required to refuel an aircraft can be reduced by increasing fuel flow rate (perhaps by increasing fueling pressure or by modifying the tank venting fuel flow valve on the aircraft).

There are also tasks that are not good candidates for R\&A because (1) they are performed very efficiently or with low workload or (2) R\&A solutions would need to be highly complex to perform those tasks. One example of such a task is canopy polishing, which is done by the plane captain while other servicing tasks are being done. R\&A would not have any impact on workload for this task, because the plane captain is in the cockpit at this time regardless of canopy polishing. R\&A would not have any impact on TAT because this task has no impact on turnaround, being performed while other tasks are in progress. Finally, R\&A solutions for this task would be fairly complex because of the perceptual and motor requirements of the task. The task is not, therefore, a good candidate for R\&A, although the task could be included as part of a comprehensive R\&A servicing installation. 


\section{Table 1. Baseline Aircraft Servicing Criterion and Task Matrix}

\begin{tabular}{|c|c|c|c|c|c|c|c|}
\hline \multirow{2}{*}{$\begin{array}{l}\text { Task: } \\
\text { Criterion }\end{array}$} & \multicolumn{4}{|c|}{ Postrecovery } & \multicolumn{3}{|l|}{ Fueling } \\
\hline & $\begin{array}{l}\text { Taxi } \\
\text { to Spot }\end{array}$ & $\mid \begin{array}{l}\text { Get Fuel } \\
\text { Status }\end{array}$ & $\mid \begin{array}{l}\text { Get A/C } \\
\text { Status }\end{array}$ & $\begin{array}{l}\text { Chock and } \\
\text { Chain }\end{array}$ & $\begin{array}{l}\text { Get Fueling } \\
\text { Readiness }\end{array}$ & $\begin{array}{l}\text { Ground } \\
\mathrm{A} / \mathrm{C}\end{array}$ & $\mid \begin{array}{l}\text { Position } \\
\text { Hose }\end{array}$ \\
\hline \multicolumn{8}{|l|}{ Task-Related } \\
\hline \multicolumn{8}{|c|}{ Manpower requirement } \\
\hline Number of "shirts" & 3 & 1 & 1 & 2 & 5 & 1 & 3 \\
\hline Workload & Low & Low & Low & High & Low & Low & High \\
\hline Safety & Fair & Good & Good & Fair & Good & Good & Fair \\
\hline Operational Tempo & Slow & Quick & Quick & Medium & Quick & Quick & Slow \\
\hline \multicolumn{8}{|l|}{ Task: } \\
\hline & Remove & Inspect & Insert & Open & Monitor & Disconnect & Stow \\
\hline Criterion & Cap & Nozzle & Nozzle & Valve & Fueling & Hose & Hose \\
\hline \multicolumn{8}{|l|}{ Task-Related } \\
\hline \multicolumn{8}{|l|}{ Manpower requirement } \\
\hline Number of "shirts" & 1 & 1 & 1 & 1 & 3 & 1 & 3 \\
\hline Workload & Low & Low & Moderate & Low & Low & Low & High \\
\hline Safety & Good & Good & Good & Fair & Good & Fair ${ }^{\circ}$ & Fair \\
\hline Operational Tempo & Medium & Quick & Quick & Quick & Slow & Quick & Slow \\
\hline
\end{tabular}

\begin{tabular}{l|l|l|l|l|l|l|l}
\hline Task: & $\begin{array}{l}\text { Maintenance and Servicing } \\
\text { Electrical } \\
\text { Connection }\end{array}$ & $\begin{array}{l}\text { Spot for } \\
\text { Loading }\end{array}$ & $\begin{array}{l}\text { Polish } \\
\text { Canopy }\end{array}$ & $\begin{array}{l}\text { Air } \\
\text { Starter }\end{array}$ & $\begin{array}{l}\text { Gas } \\
\text { Replenish }\end{array}$ & $\begin{array}{l}\text { Nav } \\
\text { Alignment }\end{array}$ & $\begin{array}{l}\text { Electrical } \\
\text { Grounding }\end{array}$ \\
\hline \hline Task-Related & & & & & & & \\
\hline Manpower requirement & & & & & & & \\
\hline Number of "shirts" & 1 & 3 & 1 & 1 & 1 & 1 & 1 \\
\hline Workload & Low & Moderate & Low & Low & Low & Low & Low \\
\hline Safety & Good & Fair & Good & Good & Good & Good & Good \\
\hline Operational Tempo & Quick & Slow & Quick & Medium & Medium & Quick & Quick \\
\hline \hline
\end{tabular}


Table 1. Baseline Aircraft Servicing Criterion and Task Matrix (continued)

\begin{tabular}{|c|c|c|c|c|c|}
\hline \multirow[t]{2}{*}{ Task: } & \multicolumn{5}{|l|}{ Loading } \\
\hline & Spread & Inspect & |Maintain & Get & Get \\
\hline Criterion & Wings & Aircraft & and Prep & Fuzes & Skids \\
\hline \multicolumn{6}{|l|}{ Task-Related } \\
\hline \multicolumn{6}{|l|}{ Manpower requirement } \\
\hline Number of "shirts" & 3 & 1 & 1 & 1 & 6 \\
\hline Workload & Low & High & Moderate & Low & High \\
\hline Safety. & Fair & Good & Fair & Good & Fair \\
\hline Operational Tempo & Moderate & Moderate & Moderate & Moderate & Slow \\
\hline
\end{tabular}

\begin{tabular}{|c|c|c|c|c|c|c|}
\hline \multicolumn{7}{|l|}{ Task: } \\
\hline & |Inspect & Transport & Position & Lift & Latch & Fuze \\
\hline Criterion & Weapon & Skid & Skid & Weapon & Weapon & Weapon \\
\hline \multicolumn{7}{|l|}{ Task-Related } \\
\hline \multicolumn{7}{|l|}{ Manpower requirement } \\
\hline Number of "shirts" & 1 & 6 & 2 & 6 & 1 & 1 \\
\hline Workload & Low & High & High & High & Low & Low \\
\hline Safety & Good & Fair & Fair & Poor & Fair & Fair \\
\hline Operational Tempo & Quick & Slow & Moderate & Moderate & Quick & Quick \\
\hline
\end{tabular}


Table 2. Tasks Sorted by Number of Persons

\begin{tabular}{|c|c|c|c|c|c|}
\hline \multicolumn{2}{|l|}{ Sorted by Shirts } & \multicolumn{4}{|l|}{ Criterion } \\
\hline Task & Subtask & $\begin{array}{l}\text { Number of } \\
\text { "shirts" }\end{array}$ & Workload & Safety & $\begin{array}{l}\text { Operational } \\
\text { Tempo }\end{array}$ \\
\hline Loading & Get Skids & 6 & High & Fair & Slow \\
\hline Loading & Transport Skid & 6 & High & Fair & Slow \\
\hline Loading & Lift Weapon & 6 & High & Poor & Moderate \\
\hline Fueling & Get Fueling Readiness & 5 & Low & Good & Quick \\
\hline Loading & Spot for Loading & 3 & Moderate & Fair & Slow \\
\hline Postrecovery & Taxi to Spot & 3 & Low & Fair & Slow \\
\hline Fueling & Monitor Fueling & 3 & Low & Good & Slow \\
\hline Loading & Spread Wings & 3 & Low & Fair & Moderate \\
\hline Fueling & Position Hose & 3 & High & Fair & Slow \\
\hline Fueling & Stow Hose & 3 & High & Fair & Slow \\
\hline Loading & Position Skid & 2 & High & Fair & Moderate \\
\hline Postrecovery & Chock and Chain & 2 & High & Fair & Medium \\
\hline Fueling & Insert Nozzle & 1 & Moderate & Good & Quick \\
\hline Loading & Maintain and Prep & 1 & Moderate & Fair & Moderate \\
\hline Postrecovery & Get Fuel Status & 1 & Low & Good & Quick \\
\hline Postrecovery & Get A/C Status & 1 & Low & Good & Quick \\
\hline Fueling & Ground $\mathrm{A} / \mathrm{C}$ & 1 & Low & Good & Quick \\
\hline Fueling & Inspect Nozzle & 1 & Low & Good & Quick \\
\hline Fueling & Open Valve & 1 & Low & Fair & Quick \\
\hline Fueling & Disconnect Hose & 1 & Low & Fair & Quick \\
\hline $\begin{array}{l}\text { Maintenance and } \\
\text { Servicing }\end{array}$ & Polish Canopy & 1 & Low & Good & Quick \\
\hline $\begin{array}{l}\text { Maintenance and } \\
\text { Servicing }\end{array}$ & Nav Alignment & 1 & Low & Good & Quick \\
\hline Loading & Inspect Weapon & 1 & Low & Good & Quick \\
\hline Loading & Latch Weapon & 1 & Low & Fair & Quick \\
\hline Loading & Fuze Weapon & 1 & Low & Fair & Quick \\
\hline Loading & Get Fuzes & 1 & Low & Good & Moderate \\
\hline Fueling & Remove Cap & 1 & Low & Good: & Medium \\
\hline Loading & Inspect Aircraft & 1 & High & Good & Moderate \\
\hline $\begin{array}{l}\text { Maintenance and } \\
\text { Servicing }\end{array}$ & Electrical Connection & & & & \\
\hline $\begin{array}{l}\text { Maintenance and } \\
\text { Servicing } \\
\end{array}$ & Air Starter & & & & \\
\hline $\begin{array}{l}\text { Maintenance and } \\
\text { Servicing }\end{array}$ & Gas Replenish & & & & \\
\hline $\begin{array}{l}\text { Maintenance and } \\
\text { Servicing }\end{array}$ & Electrical Grounding & & & & \\
\hline $\begin{array}{l}\text { Maintenance and } \\
\text { Servicing }\end{array}$ & Oil \& Hydraulic & & & & \\
\hline Loading & Load Stores & & & & \\
\hline Loading & Load Countermeasures & & & & \\
\hline
\end{tabular}


Table 3. Tasks Sorted by Workload

\begin{tabular}{|c|c|c|c|c|c|}
\hline \multicolumn{2}{|c|}{ Sorted by Workload } & \multicolumn{4}{|l|}{ Criterion } \\
\hline Task & Subtask & $\begin{array}{l}\text { Number of } \\
\text { "shirts" }\end{array}$ & Workload & Safety & $\begin{array}{l}\text { Operational } \\
\text { Tempo }\end{array}$ \\
\hline Loading & Get Skids & 6 & High & Fair & Slow \\
\hline Loading & Transport Skid & 6 & High & Fair & Slow \\
\hline Loading & Lift Weapon & 6 & High & Poor & Moderate \\
\hline Fueling & Position Hose & 3 & High & Fair & Slow \\
\hline Fueling & Stow Hose & 3 & High & Fair & Slow \\
\hline Loading & Position Skid & 2 & High & Fair & Moderate \\
\hline Postrecovery & Chock and Chain & 2 & High & Fair & Medium \\
\hline Loading & Inspect Aircraft & 1 & High & Good & Moderate \\
\hline Loading & Spot for Loading & 3 & Moderate & Fair & Slow \\
\hline Fueling & Insert Nozzle & 1 & Moderate & Good & Quick \\
\hline Loading & Maintain and Prep & 1 & Moderate & Fair & Moderate \\
\hline Fueling & Get Fueling Readiness & 5 & Low & Good & Quick \\
\hline Postrecovery & Taxi to Spot & 3 & Low & Fair & Slow \\
\hline Fueling & Monitor Fueling & 3 & Low & Good & Slow \\
\hline Loading & Spread Wings & 3 & Low & Fair & Moderate \\
\hline Postrecovery & Get Fuel Status & 1 & Low & Good & Quick \\
\hline Postrecovery & Get A/C Status & 1 & Low & Good & Quick \\
\hline Fueling & Ground $\mathrm{A} / \mathrm{C}$ & 1 & Low & Good & Quick \\
\hline Fueling & Inspect Nozzle & 1 & Low & Good & Quick \\
\hline Fueling & Open Valve & 1 & Low & Fair & Quick \\
\hline Fueling & Disconnect Hose & 1 & Low & Fair & Quick \\
\hline $\begin{array}{c}\text { Maintenance and } \\
\text { Servicing }\end{array}$ & Polish Canopy & 1 & Low & Good & Quick \\
\hline $\begin{array}{c}\text { Maintenance and } \\
\text { Servicing }\end{array}$ & Nav Alignment & 1 & Low & Good & Quick \\
\hline Loading & Inspect Weapon & 1 & Low & Good & Quick \\
\hline Loading & Latch Weapon & 1 & Low & Fair & Quick \\
\hline Loading & Fuze Weapon & 1 & Low & Fair & Quick \\
\hline Loading & Get Fuzes & 1 & Low & Good & Moderate \\
\hline Fueling & Remove Cap & 1 & Low & Good & Medium \\
\hline \begin{tabular}{|c|} 
Maintenance and \\
Servicing \\
\end{tabular} & Electrical Connection & & & & \\
\hline \begin{tabular}{|c|} 
Maintenance and \\
Servicing \\
\end{tabular} & Air Starter & & & & \\
\hline \begin{tabular}{|c|} 
Maintenance and \\
Servicing
\end{tabular} & Gas Replenish & & & & \\
\hline $\begin{array}{c}\text { Maintenance and } \\
\text { Servicing }\end{array}$ & Electrical Grounding & & & & \\
\hline \begin{tabular}{|c} 
Maintenance and \\
Servicing
\end{tabular} & Oil \& Hydraulic & & & & \\
\hline Loading & Load Stores & & & & \\
\hline Loading & Load Countermeasures & & & & \\
\hline
\end{tabular}


Table 4. Tasks Sorted by Operational Tempo

\begin{tabular}{|c|c|c|c|c|c|}
\hline \multicolumn{2}{|l|}{ Sorted by Tempo } & \multicolumn{4}{|l|}{ Criterion: } \\
\hline Task & Subtask & $\begin{array}{l}\text { Number of } \\
\text { "shirts" }\end{array}$ & Workload & Safety & $\begin{array}{l}\text { Operational } \\
\text { Tempo }\end{array}$ \\
\hline Loading & Get Skids & 6 & High & Fair & Slow \\
\hline Loading & Transport Skid & 6 & High & Fair & Slow \\
\hline Fueling & Position Hose & 3 & High & Fair & Slow \\
\hline Fueling & Stow Hose & 3 & High & Fair & Slow \\
\hline Loading & Spot for Loading & 3 & Moderate & Fair & Slow \\
\hline Postrecovery & Taxi to Spot & 3 & Low & Fair & Slow \\
\hline Fueling & Monitor Fueling & 3 & Low & Good & Slow \\
\hline Loading & Lift Weapon & 6 & High & Poor & Moderate \\
\hline Loading & Position Skid & 2 & High & Fair & Moderate \\
\hline Loading & Inspect Aircraft & 1 & High & Good & Moderate \\
\hline Loading & Maintain and Prep & 1 & Moderate & Fair & Moderate \\
\hline Loading & Spread Wings & 3 & Low & Fair & Moderate \\
\hline Loading & Get Fuzes & 1 & Low & Good & Moderate \\
\hline Postrecovery & Chock and Chain & 2 & High & Fair & Moderate \\
\hline Fueling & Remove Cap & 1 & Low & Good & Moderate \\
\hline Fueling & Insert Nozzle & 1 & Moderate & Good & Quick \\
\hline Fueling & Get Fueling Readiness & 5 & Low & Good & Quick \\
\hline Postrecovery & Get Fuel Status & 1 & Low & Good & Quick \\
\hline Postrecovery & Get A/C Status & 1 & Low & Good & Quick \\
\hline Fueling & Ground $\mathrm{A} / \mathrm{C}$ & 1 & Low & Good & Quick \\
\hline Fueling & Inspect Nozzle & 1 & Low & Good & Quick \\
\hline Fueling & Open Valve & 1 & Low & Fair & Quick \\
\hline Fueling & Disconnect Hose & 1 & Low & Fair & Quick \\
\hline $\begin{array}{l}\text { Maintenance and } \\
\text { Servicing }\end{array}$ & Polish Canopy & 1 & Low & Good & Quick \\
\hline $\begin{array}{l}\text { Maintenance and } \\
\text { Servicing }\end{array}$ & Nav Alignment & 1 & Low & Good & Quick \\
\hline Loading & Inspect Weapon & 1 & Low & Good & Quick \\
\hline Loading & Latch Weapon & 1 & Low & Fair & Quick \\
\hline Loading & Fuze Weapon & 1 & Low & Fair & Quick \\
\hline $\begin{array}{l}\text { Maintenance and } \\
\text { Servicing }\end{array}$ & Electrical Connection & & & & \\
\hline $\begin{array}{l}\text { Maintenance and } \\
\text { Servicing }\end{array}$ & Air Starter & & & & \\
\hline $\begin{array}{l}\text { Maintenance and } \\
\text { Servicing }\end{array}$ & Gas Replenish & & & & \\
\hline $\begin{array}{l}\text { Maintenance and } \\
\text { Servicing }\end{array}$ & Electrical Grounding & & & & \\
\hline $\begin{array}{l}\text { Maintenance and } \\
\text { Servicing }\end{array}$ & Oil \& Hydraulic & & & & \\
\hline Loading & Load Stores & & & & \\
\hline Loading & Load Countermeasures & & & & \\
\hline
\end{tabular}





\section{R\&A CONCEPTS}

A set of concepts for R\&A applied to flight desk tasks is outlined subsequently. The tasks for which R\&A concepts were generated are those that are manpower intensive and could realize the largest LCC savings. The tasks for which concepts were generated are fueling, ammunition storage, ammunition loading, ammunition transport, aircraft tiedown, and plane spotting. In each case the baseline against which the concepts should be examined is the current procedure and equipment. The current procedure is briefly outlined in each task section. Some of the following concepts are not worth pursuing because they are not an improvement over current procedures. At the end of each task section there is a table rating the relative merits of the listed design options. At this stage in the selection process the rating is subjective.

\subsection{Fueling}

Fueling is currently performed using hoses supplied from deck edge stations. Hoses are coupled together to the desired length and are mounted on a deck-side reel. Hoses come in 150-ft lengths, and the entire $150 \mathrm{ft}$ must be deployed to fuel (even if only $20 \mathrm{ft}$, for example, is needed). Fueling is performed using a minimum crew of three. One person mans the deck edge station and controls the valve supplying the hose. One crewman, the hose handler, helps handle the hose. Finally, the nozzle operator attaches the nozzle to the aircraft. Both the nozzle operator and hose handler are required for hose handling. Fueling a typical aircraft takes about 15 minutes because of fuel flow-rate limitations, which are determined by the aircraft vents.

\subsubsection{Improved Hose and Valve}

Improvements could be made to the current deck-side fueling station to remove the need to man the deck-edge station. The changes would be the addition of automated valving at the deck edge station and a control pendant on the nozzle. The nozzle pendant would control fuel flow to the airplane and draining the fuel out of the hose. The hose would include the current continuity check. A deadman feature could also be added to stop fueling whenever the nozzle operator releases the deadman switch.

\subsubsection{Pantograph}

One possibility for easing hose handling is to use a pantograph. The pantograph could be attached to either the current deck-side fueling station or to a new fueling station as described in the "improved hose and valve" section. The pantograph could allow for elimination of the hose handler. This concept will not be considered further, however, because of the difficulty in moving the rigid pantograph segments around parked, closely spaced aircraft. Another reason for rejecting this concept is that the rigid pantograph segments could swing into and damage aircraft during heavy sea states. 


\subsubsection{Cart Equipped with Short Hoses}

An alternative concept is a small cart equipped with short hoses about $20-30 \mathrm{ft}$ long. One hose would go from the cart to a fuel port either in the flight deck or on the deck edge. One or two hoses on the cart would go to the airplanes being fueled. All the valving for fueling, with the exception of a cutoff valve on the fuel port, would be on the cart, simplifying the design of the fuel ports. Beside the fuel port would be a de-fueling port to allow aircraft de-fueling. The hose reels could be motorized, further reducing the workload necessary to deploy the hoses. The hose nozzle could incorporate the features described in the "improved hose and valve section" to further reduce workload.

\subsubsection{Robotic Servicing Station}

Another possibility is an automated servicing station that integrates fueling and ammunition handling. The degree of automation could range from a power assist (man amplification) for human operators to full automation. This option will not be considered further. Limited deck space restricts the number of servicing stations possible, in turn limiting the possible redundancy in the event of a station failure. The fixed position of the servicing station also limits the flexibility of aircraft positioning on the flight deck.

\subsubsection{Hose "Weasel"}

Fueling is labor intensive, requiring a minimum of three persons (fueling station operator, nozzle operator, and plane captain) and more often requiring four persons (an additional hose handler). There are stresses placed on the hose during deployment, and difficulties deploying long hoses around aircraft. Although there are several tasks required for fueling, some of these (e.g., opening and inspecting the fueling port, inserting and latching the nozzle, and grounding the aircraft) are not amenable to R\&A because of complex sensorimotor requirements or low workload. The task that might benefit most from R\&A is deploying the hose, that is, dragging it off of the reel to the airplane and back. One robotics assistant that might work is a small cart that could drag the hose from reel to airplane and back. This "hose weasel" could attach itself near the nozzle and drag the hose, allowing the nozzle operator to (1) walk alongside or (2) walk from airplane to airplane. This would not reduce the minimum fueling personnel requirement but would reduce the typical fueling team by one person.

The hose weasel could be an autonomous robot, driving itself from station to airplane and from airplane to airplane, or it could be a "come along" device pulled by the nozzle operator. The device could also perform some other tasks, such as setting the quick disconnect check switches, monitoring flow rate, and turning the fueling valves (one now at the fueling station and one at the nozzle) on and off at the proper times. Given enough functionality, it could (1) replace or reduce the workload of the fueling station operator and (2) allow one nozzle operator to work on adjacent airplane simultaneously (by allowing the operator to function as a monitor, after nozzle and grounding connections are made). 


\subsection{Ammunition Storage}

Munitions ready to be loaded onto the planes are stored starboard of the island, in an area called the bomb farm. A problem with the current storage method is limited capacity. Storage capacity is typically adequate for the first two daily cycles when conducting cyclic operations. During successive cycles, however, operations start to be delayed because of the limited strike up capacity, from the magazines to the flight deck.

\subsubsection{Storage Cells}

Although not strictly a flight deck improvement, applying a "just in time" manufacturing model to ammunition could be beneficial, particularly if coupled with R\&A solutions in transport and loading. Currently, munitions are delivered on skids from the buildup area. This could be made more efficient by building up munitions at the 03 level and delivering them to the deck as they are needed. This could take better advantage of the greater speed and reduced workload of the transport concepts discussed subsequently.

Ammunition buildup could be improved by placing a storage area in the 03 level. The storage area would consist of racks for storage of the ammunition accessed by sideloading forklifts. The storage racks would allow for stacking munitions multiple levels high. Side-loading forklifts would be used to reduce the space required by the forklifts. Storing additional ammunition on the flight deck raises a safety concern. This concern could be reduced, however, by putting shielding between the storage cells to reduce explosion propagation.

It may also be possible to increase the capacity of the bomb farm, which would buffer the limited flow rate possible from below decks. Stacked storage cells at the site of the current bomb farm could be designed with an integrated robotic arm to permit hoisting a skid and munition into each cell. These could be retrieved as required and placed on the deck for manual transport, or onto motorized skid movers for assisted transport.

\subsection{Ammunition Loading}

For the most part, ammunition is currently loaded by hand, perhaps with motorized assistance by means of tools like the HLU-196B/E bomb hoist. Hand loading requires getting enough crewmen to lift the weapon and place it onto the rack. The R\&A concepts presented subsequently apply more advanced technology to this physically demanding and safety-critical task.

\subsubsection{Robotic Bomb Arm}

This concept is an outgrowth of the Next Generation Munitions Handler (NGMH). The system would lift a munition, or a skid with its munition, up to the rack. The system would include enough degrees of freedom to acquire the munition from the skid, or the skid and munition together, and enough precision and payload capacity to allow positioning the munition onto the rack. 
A robotic manipulator working on a man-amplification scheme could reduce the number of persons required to place the munition on an airplane. If the manipulator was integrated into a skid, it could also reduce the workload (and, perhaps, improve efficiency) at the buildup area or transfer station and make loading easier and more efficient.

\subsubsection{Robotic Servicing Station}

An automated servicing station integrating fueling and ammunition handling has been described in the preceding discussion of solutions for fueling.

\subsection{Flight Deck Ammunition Transport}

Currently, ammunition is manually moved around on the flight deck using wheeled skids. Typically there is one munition per skid and at least one crewman to move each skid. As the skids are unpowered, munitions are moved along the deck at walking speed. Munitions are typically moved from the bomb farm to the aircraft. Because of respotting aircraft, it might be necessary to manually move a munition several thousand feet on the flight deck before finally loading onto the aircraft. The limited space on the flight deck limits potential alternatives.

\subsubsection{Internal Conveyor With Deck Edge Stations}

Ammunition would be moved along the flight deck by transferring it from a buildup area (possibly at the 03 level) to an under-deck conveyor. The ammunition would be conveyed under the flight deck to another deck-edge station where the ammunition would be removed. Ammunition transfer rates in the conveyor could be much greater than for the current skid pulling method. This system would also be used when moving ammunition from the bow to the fantail when aircraft are re-spotted.

\subsubsection{Robotic Servicing Station}

Another possibility is an automated servicing station that integrates fueling and ammunition handling. Degree of automation could range from power assist (man amplification) for human operators to full automation. The robotic servicing station would remove the need to transfer ammunition along the flight deck because the station would be the only destination for ammunition transfers. This option will not be considered further. Limited deck space restricts the number of possible servicing stations, limiting redundancy in the event of a station failure. The fixed position of the servicing station also limits the flexibility of aircraft positioning on the flight deck.

\subsubsection{Motorized Skid Mover}

The current ammunition skids are moved manually, one munition per skid along the deck at walking speed. Movement speed out on the flight deck itself can probably not be significantly increased because of the congestion on the flight deck. Although speeds cannot be significantly improved, loads could be increased using some mechanical assistance. The device would resemble motorized pallet movers used in warehouses. To 
minimize ammunition transfer, the larger munitions transport systems would have to be compatible with under-deck equipment. An example would be a device which several skids and their munitions could be rolled onto and off of, before and after transport on the deck.

\subsubsection{Self Skid}

Ammunition loading is labor intensive because of the manner in which munitions are retrieved from the bomb farm and the manner in which munitions are loaded on the airplane. R\&A could help in this area in at least two ways. Munitions loading requires two "ordies" (minimum) to drag a skid from the bomb farm, return it to the airplane and position it under a station, and then hoist the munition into position and latch it onto a bomb rack. In the area of transport, a "self skid" that automatically travels between the bomb farm and aircraft spots (or designated points near the spotting points) could remove the need for two persons to transport munitions back and forth. A skid with a mobility platform capable of stepping over hoses would also be helpful, because currently fuel hoses on the deck must be lifted over a skid to allow it to pass.

However, the complexity and risk of developing such an autonomous system are high, and the maintenance requirements are more than for other options. A better concept would be a motorized skid equipped with "come along" capability to allow a single crewman to acquire and move a skid (or set of skids; see "4.4.5. Skid Trains" and "4.4.3. Motorized Skid Mover").

\subsubsection{Skid Trains}

Munitions transport is labor intensive in part because two ordies must go back and forth for a single munition. If motorized skids could be developed, these skids could be organized into skid "trains" to reduce workload even more. Instead of, for example, two people making two trips with a skid to retrieve a pair of $500-1 b$ bombs, one person might be able to retrieve both bombs in a single trip. The trains could be any size, provided arrangements could be made for a single operator to control all of the skids. However, given deck space limitations, trains of two or three skids are likely to be more practical. Such an arrangement would, in the example of a two-skid train, double the footprint of the moving skids but would not necessarily increase the storage footprint of the individual skids. This arrangement would yield a potential workload savings of three ordies, in the two-skid case.

\subsubsection{Remora Skid}

The principle objection to large skids (e.g., a skid capable of carrying several munitions, even the sum total of munitions for a particular airplane) is that such vehicles would take up too much deck space. However, if a skid could be developed that took up no deck space, or that used deck space already occupied, this objection might be overcome. A remora is a fish that attaches itself to another fish. A remora skid would be one that, already loaded with munitions, drives or is driven out to an aircraft, slides in beneath it, and goes where the aircraft goes. The skid could even be tied into the aircraft's control computer so that pilot control inputs could be translated to skid 
movements. Once the aircraft is spotted and tied down, the remora skid could emerge and be used to attach munitions to that airplane. It may even be possible to reduce skid count and deck space by designing a remora skid that could rearm two aircraft, so that remora skids need only attach themselves to every other airplane. The advantages of the remora skid are (1) it uses deck space already occupied by an aircraft and (2) it obviates the necessity for multiple trips to the bomb farm. Since the skids could be loaded at the buildup area, or sent up to the flight deck on elevators as complete packages, it may even be possible to do away with the bomb farm using this approach.

As an expansion on the large skid concept, a skid could be designed to deploy retractable support structures for munitions and fold those structures for transport while empty. This would allow a loaded skid to carry a full aircraft load of munitions while under the aircraft, but permit the empty skid returning to the bomb farm or elevator to have a much smaller footprint.

\subsection{Aircraft Tie Down}

Aircraft are tied down before any servicing or loading task. Depending on the aircraft and the sea state, 6 to 24 tie-downs are required. The tie-down is metal. Tiedowns have a hook at each end, a metal chain connecting the two hooks, and a tensioning mechanism.

\subsubsection{KEVLAR@* Tiedown}

To reduce the weight of the tie down and increase the number of tie downs a single crewman can handle, substituting KEVLARß webbing for the metal chain is suggested.

\subsection{Plane Spotting}

Moving airplanes on the flight deck is a manpower intensive operation. The minimum crew required to move an aircraft is a brake rider (plane captain), tractor operator, two chockmen/chain handlers, and two wing-tip safety handlers. The equipment required is a tractor, tow bar, chocks, and tie-downs.

\subsubsection{Omnidirectional Tractor with Integrated Towbar}

The current tractor-tow bar combination could be replaced with an omnidirectional tractor and an integrated towing mechanism. The tractor would be similar to the mobility platform developed for the Air Force NGMH demonstration. In operation, the tractor would be driven up to the aircraft nose wheel and the nose wheel would be attached to the tractor and lifted up off the deck. With the aircraft nose wheel lifted off the deck and the omnidirectional capabilities of the tractor, an aircraft could be maneuvered in tighter quarters. This arrangement does not, however, reduce required manpower. It does have the potential to reduce towing system footprint, compared to current tractors, and provide better towing maneuverability. The latter may improve the efficiency of re-spotting and reduce TAT.

\footnotetext{
${ }^{*}$ KEVLAR is a DuPont registered trademark.
} 


\subsubsection{In-deck Cable}

A possible alternative to tractors for re-spotting is a cable running in the deck in an endless loop. Aircraft could be attached to the cable and towed from the bow to the fantail. This option is not worth pursuing, however, because of deck obstructions (arresting gear, catapults) and the limited parking arrangements possible. 


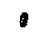




\section{PERFORMANCE COMPARISONS FROM SIMULATION}

The performance of select R\&A concepts was modeled using task network simulation. Concepts judged to have the best chance of improving LCC or TAT, and the best technical feasibility, were selected for detailed task network modeling. The impact of increasing fuel flow was also included to illustrate the potential savings of that nonR\&A option. Simulation runs were conducted to identify potential savings in LCC or TAT within the task addressed by the concept (e.g., the impact of a motorized skid on weapon loading) and on total TAT. For each simulation, a single task was modified and all other tasks were modeled as for the baseline.

The models recorded two criteria. Task completion time and subtask completion time are straightforward, being simply a difference between the system clock at the start of a particular task or subtask and the system clock at the end of that task or subtask. Workload is recorded by summing the products of the number of crewmen employed by the time to complete for each subtask. Because subtasks may be running simultaneously and some may be completed before others, workload is not a straightforward product of crew employed and task completion time. Workload must be calculated at the subtask level and summed at the task level to be representative. For example, in the real world it is possible for six crewman to be transporting munitions while two other crewmen wait for them at the aircraft. "Standing around" time should not be counted as workload for comparison of loading methods (although it may be a valuable criterion itself; the less the "standing around" time, the fuller the employment of the crew). The task network models accounts for this by recording workload for each subtask and crewman separately.

Task performance estimates have not been validated against real-world performance, and model parameters are a combination of subject matter experts' opinions and best engineering judgement (based on experience with human performance with robotic systems). Therefore, the results of these simulation runs should not be taken as evidence for future LCC and TAT savings that will result from the deployment of robotic systems. Rather, they should be taken as further evidence that R\&A applied to flight deck servicing tasks can improve LCC and TAT for the tasks modeled.

\subsection{Concepts Simulated}

For each concept, a modification of the baseline aircraft servicing network model was created to reflect anticipated performance changes for that concept, from the baseline. A set of 1,000 simulation runs was conducted using each model. Estimates of crew workload and task completion time for fueling and weapons loading subtasks were calculated, along with total servicing time.

\subsubsection{Baseline}

The baseline model is included for comparison. Task networks for the baseline are included in the appendix. 


\subsubsection{1-Man Motorized Skid}

This model represent performance of weapons loading with a motorized skid or a motorized skid mover, making it possible for a single crewman to acquire the skid, move it to the aircraft, position it beneath the aircraft hardpoint, and raise the weapon. This model may is representative of both the motorized skid mover and of the "Self Skid" concepts described above. Within this model, a single crewman is assumed responsible for moving each munition to the aircraft. The baseline assumed a team of 6 crewmen moving munitions to the aircraft, 2 crewmen per skid. In the 1-man motorized skid model, 3 crewmen were assumed to be performing the same work, but with the assistance of motorized skids (or skid movers). Within this and all other models, 8 munitions are loaded onto the aircraft.

\subsubsection{Double}

This model assumes a skid or skid mover capable of transporting 2 munitions at the same time. Because of the increase capability per crewman (one man moving two munitions at a time) it reduces the munitions transport crew to a single person per aircraft. It is representative of the motorized skid mover and the "Self Skid," coupled with the "Skid Trains" approach to moving several munitions at once.

\subsubsection{Double}

This model assumes a skid or skid mover capable of transporting 2 munitions at the same time, as for the "1 Double" model. It differs in that it adds a second skid/crewman combination, that is, 2 munitions transporters per aircraft.

\subsubsection{Remora}

A remora skid would be one that, already loaded with munitions, drives or is driven out to an aircraft, slides in beneath it, and goes where the aircraft goes. This concept could also include robotic manipulator arms capable of positioning and hoisting munitions into place. The Remora task network model simulates the performance of that concept.

\subsubsection{Fast Fuel}

The fast fuel model is the same as the baseline except that a fuel flow of twice the current practice is used in the refueling task.

\subsubsection{Fuel "Weasel"}

This model simulates the impact of a robotic refueling hose cart, designed to improve the efficiency of deploying hoses to aircraft. 


\subsection{Results}

Table 5 presents the results of the task network simulation runs. Within the table, the first column lists the concepts modeled. The second and third columns present the performance of each concept relative to the baseline during the fueling subtask for workload and completion time, respectively. The fourth and fifth columns present performance during the munitions loading task for workload and completion time. The sixth column presents relative task completion time for complete servicing of a single aircraft, and the final column provides some descriptive notes about the concept modeled.

\section{Table 5. Results of Task Network Simulation Runs}

\begin{tabular}{|c|c|c|c|c|c|c|}
\hline \multirow[b]{3}{*}{ Condition } & \multicolumn{4}{|c|}{ Sub-task } & \multirow{3}{*}{$\begin{array}{l}\text { Total } \\
\text { Time } \\
\end{array}$} & \multirow[b]{3}{*}{ Notes } \\
\hline & \multicolumn{2}{|c|}{ Fuel } & \multicolumn{2}{|c|}{ Load } & & \\
\hline & Workload & Time & Workload & Time & & \\
\hline Baseline & $100 \%$ & $100 \%$ & $100 \%$ & $100 \%$ & $100 \%$ & $\begin{array}{l}\text { Baseline model is current } \\
\text { technology and } \\
\text { practices }\end{array}$ \\
\hline $\begin{array}{l}\text { 1-Man } \\
\text { Motorized } \\
\text { Skid }\end{array}$ & $100 \%$ & $100 \%$ & $78 \%$ & $100 \%$ & $100 \%$ & $\begin{array}{l}\text { 1-Man skid is a motorized } \\
\text { "come along" skid } \\
\text { operated by a single } \\
\text { crewman, } 3 \text { per aircraft }\end{array}$ \\
\hline 1 Double & $100 \%$ & $100 \%$ & $76 \%$ & $167 \%$ & $117 \%$ & $\begin{array}{l}\text { 1-man motorized skid } \\
\text { carrying } 2 \text { weapons, } 1 \\
\text { man per aircraft }\end{array}$ \\
\hline 2 Double & $100 \%$ & $100 \%$ & $69 \%$ & $92 \%$ & $98 \%$ & $\begin{array}{l}\text { As for } 1 \text { Double, but } 2 \\
\text { crewman per aircraft }\end{array}$ \\
\hline Remora & $100 \%$ & $100 \%$ & $61 \%$ & $79 \%$ & $96 \%$ & $\begin{array}{l}\text { Remora skid...taxis along } \\
\text { with aircraft and } \\
\text { underneath it }\end{array}$ \\
\hline Fast Fuel & $70 \%$ & $67 \%$ & $100 \%$ & $100 \%$ & $84 \%$ & $\begin{array}{l}\text { Fast fuel is a model } \\
\text { requiring half as much } \\
\text { time to refuel }\end{array}$ \\
\hline $\begin{array}{l}\text { Fuel } \\
\text { "Weasel" }\end{array}$ & $92 \%$ & $96 \%$ & $100 \%$ & $100 \%$ & $98 \%$ & $\begin{array}{l}\text { Robotic cart for deploying } \\
\text { hoses }\end{array}$ \\
\hline
\end{tabular}

Because these models, including the baseline model, are parameterized using expert opinions and best engineering judgement, and because they have not been validated against real-world observations, the results are presented as percentages of the baseline. The numbers presented in the table should not be taken as evidence that the R\&A solutions will improve performance, but rather as indicators of the potential of each concept for improving performance.

\subsubsection{1-Man Motorized Skid}

The 1-man motorized skid showed, on average, an improvement in the workload associated with loading munitions. The loading task required only $78 \%$ of the workload required for the same task in the baseline model, without affecting the time required to 
complete the task. There was no effect on overall servicing time. It appears that this approach is capable of reducing LCC by reducing workload, without a deleterious affect on TAT. This was the result of reducing the munitions transport crew by half within the munitions transport subtask of the loading task.

\subsubsection{Double}

The 1 Double concept evaluated the possibility of reducing the munitions transport crew to a single person, provided with a motorized assistance for moving skids and the capability of moving 2 munitions at a time. The loading task required only $76 \%$ of the workload required by the same task in the baseline model, but it took much longer $(167 \%)$ to complete. This resulted in total servicing time that was $117 \%$ longer than for the baseline.

This concept showed a reduction in workload, compared to the baseline, because of the reduction in the crew size necessary for loading. However, it also required more from the single person left to transport munitions. The concept increased loading time because, at any one time, only a single munition was being uploaded onto the aircraft; and because the load crew could not build up a queue of more than 2 munitions waiting at the aircraft for upload. While the single person responsible for munitions transport was in transit between aircraft and bomb farm, no loading work was taking place at the aircraft. For the other models, there were more munitions in the queue and while one transport crewman was in transit others were at the aircraft with munitions ready for upload.

The reduction in workload is the result of further reducing the size of the munitions transport crew. However, this had the affect of requiring longer to complete loading. It appears that this option may be capable of reducing LCC by reducing workload, although the impact of slower TAT on LCC and overall flight operations was not modeled.

\subsubsection{Double}

The 2 Double concept applies the same technology as the 1 Double concept, but is less aggressive in reducing crew size. It features the same motorized assistance for skid moving and the multiple-munitions capability. However, it assumes that 2 crewmen will be moving munitions for each airplane. For this concept, the loading task required only $69 \%$ of the workload required for the task in the baseline model, and it required only $92 \%$ of the time required to complete loading in the baseline model. This concept also reduced total servicing time, requiring only $92 \%$ as long as for the baseline. This concept appears to have potential for decreasing both TAT and LCC during flight-deck servicing operations.

\subsubsection{Remora}

The Remora concept model showed the greatest reduction in workload and time for the loading task. Workload was only $61 \%$ of the baseline and the average time that was required to complete the task was only $79 \%$ of the baseline. This concept reduced total servicing time to $96 \%$ of the baseline. 
This concept appears to have potential for decreasing both TAT and LCC during flight-deck servicing operations. However, the possible size of the vehicle and its impact on the flight deck was not modeled in this study. This concept requires fairly complex technology, and the risks of further development along this line are not clear. Further modeling, including task network modeling to validate performance requirements and virtual concept development to clarify physical constraints and impacts, is necessary to understand all the implications of this concept.

\subsubsection{Fast Fuel}

From table 5, it appears that increasing fuel flow can produce the greatest potential reduction in TAT. Doubling the fuel flow rate in the model led to workload that was $70 \%$ of the baseline and refueling time that was $67 \%$ of the baseline. Workload reduction stems solely from the reduction in refueling time, which reduces the amount of time that the crew is devoted to observing the refueling. Total servicing time was $84 \%$ of the baseline for the fast fuel model. This concept appears to have potential for decreasing both TAT and LCC during flight-deck servicing operations.

\subsubsection{Fuel "Weasel"}

The fuel weasel or robotic refueling cart reduced workload to $92 \%$ of the baseline and fueling time to $96 \%$ of the baseline. Total servicing time was $98 \%$ of the baseline. This concept appears to have potential for decreasing both TAT and LCC during flightdeck servicing operations.

\subsection{Task Network Simulation Summary}

All of the advanced concepts simulated improved servicing task performance, and most of them either improved overall servicing time or did not affect it. The exception to that is the " 1 Double" concept, in which a single crewman is responsible for all of the skid transports necessary for loading. The latter showed decreased workload but increased loading and total servicing time. From these data, it appears that the potential exists for R\&A alternatives for the selected tasks have the potential for reducing lifecycle costs, and most have the potential to reduce TAT, as well.

Two caveats must be mentioned, however. First, the performance parameters entered into the baseline model are estimates from subject matter experts. Actual task timing data could not be found at the level necessary for task network simulation. The models presented here must be validated using actual task timing data to produce accurate estimates for the baseline conditions. Second, the performance of the R\&A concepts cannot be estimated accurately without further concept development. Therefore, while the performance results described in this section indicate that there is potential for LCC savings and TAT reductions, the actual savings and reductions cannot be estimated at this time. 



\section{SUMMARY AND CONCLUSIONS}

\subsection{Summary}

We have taken a bottom-up, task-oriented approach to identifying areas for aircraft servicing improvements. The study began by identifying aircraft servicing tasks that have high workload or low efficiency as possible candidates for R\&A alternatives. This approach allows future developments to be aimed at tasks that can benefit most from advanced technology, ensuring that R\&A development has a high potential payback in terms of LCC reductions. This study demonstrates that improvements to flight deck servicing, leading to LCC reductions, are possible through the application of robotics and automation, both for existing aircraft carriers and future carriers.

Task lists and task network models point to candidates for R\&A-based LCC or TAT improvements. The highest potential seems to exist in munitions handling tasks, where workload is high and R\&A concepts featuring the state of the art (SOA) in perception and cognition can be successful, and in fueling.

Full automation of these tasks is probably not viable: perceptual and cognitive demands are too great for current SOA. This points to integrated sailor-robot systems that combine the perceptual and cognitive capabilities of humans with the movement capabilities of heavy-lift, dexterous robotics.

Preliminary solutions involving human-robot systems have been identified. These are examples of what may be done but require further study to validate the technical feasibility and corresponding LCC savings.

Improvements outside of the current scope also seem possible. This study had the mission of examining aircraft servicing in the context of existing aircraft carrier flight decks. More pervasive R\&A solutions involving changes in the flight and hangar decks themselves may also be possible but are outside of the scope of this study.

\subsection{High-Need Tasks}

From the study, the following servicing tasks were identified as having the highest potential for improvement through application of R\&A solutions:

- Loading: Get Skids

- Loading: Transport Skid

- Loading: Lift Weapon

- Fueling: Position Hose

- Fueling: Stow Hose

- Loading: Spot for Loading

- Postrecovery: Taxi to Spot

- Loading: Position Skid

- Fueling: Monitor Fueling

- Loading: Spread Wings

- Postrecovery: Chock and Chain 


\subsection{R\&A Risk}

Development of R\&A solutions must include an evaluation of the risk of such developments, in the context of the SOA. The application of R\&A requires an understanding of the perceptual, cognitive, and movement requirements for a task so that the capabilities of the SOA can be evaluated. Each R\&A concept has been evaluated, and the risk associated with the concept has been identified, but only in a preliminary fashion. Further, more detailed development of concepts is necessary to truly understand the risk of R\&A solutions for application to the very stringent and unstructured environment of existing flight decks.

\subsection{Legacy Carriers and $R \& A$}

Certain R\&A concepts are not amenable to application to existing flight decks, at least not without significant modification. Among these are (1) an internal munitions conveyor, (2) an integrated robotics servicing station, and (3) an in-deck cable for aircraft spotting. The other R\&A solutions mentioned are applicable to existing and future carriers.

\subsection{Conclusions}

Robotics and automation can improve the LCC of operating aircraft carriers in the context of the flight deck servicing tasks studied here. Task analysis and task network modeling contribute to an evaluation of existing servicing tasks and point to tasks amenable to R\&A and that are possible with the current SOA.

Future work should buttress and extend these findings by taking the following steps:

- Validate the baseline task network model against actual flight deck servicing to improve the accuracy of performance estimates.

- Develop the R\&A concepts in further detail, and explore further R\&A concepts to improve the accuracy of performance enhancement predictions from task network modeling.

- Develop virtual models of the R\&A concepts to assist in identifying concepts worthy of development and to understand the interaction of R\&A systems with existing flight deck equipment and personnel.

- Develop technology demonstrators for high-priority concepts to ascertain and demonstrate the robotics technology needed for future flight deck operations. 


\section{APPENDIX: TASK NETWORK MODEL EXAMPLES}

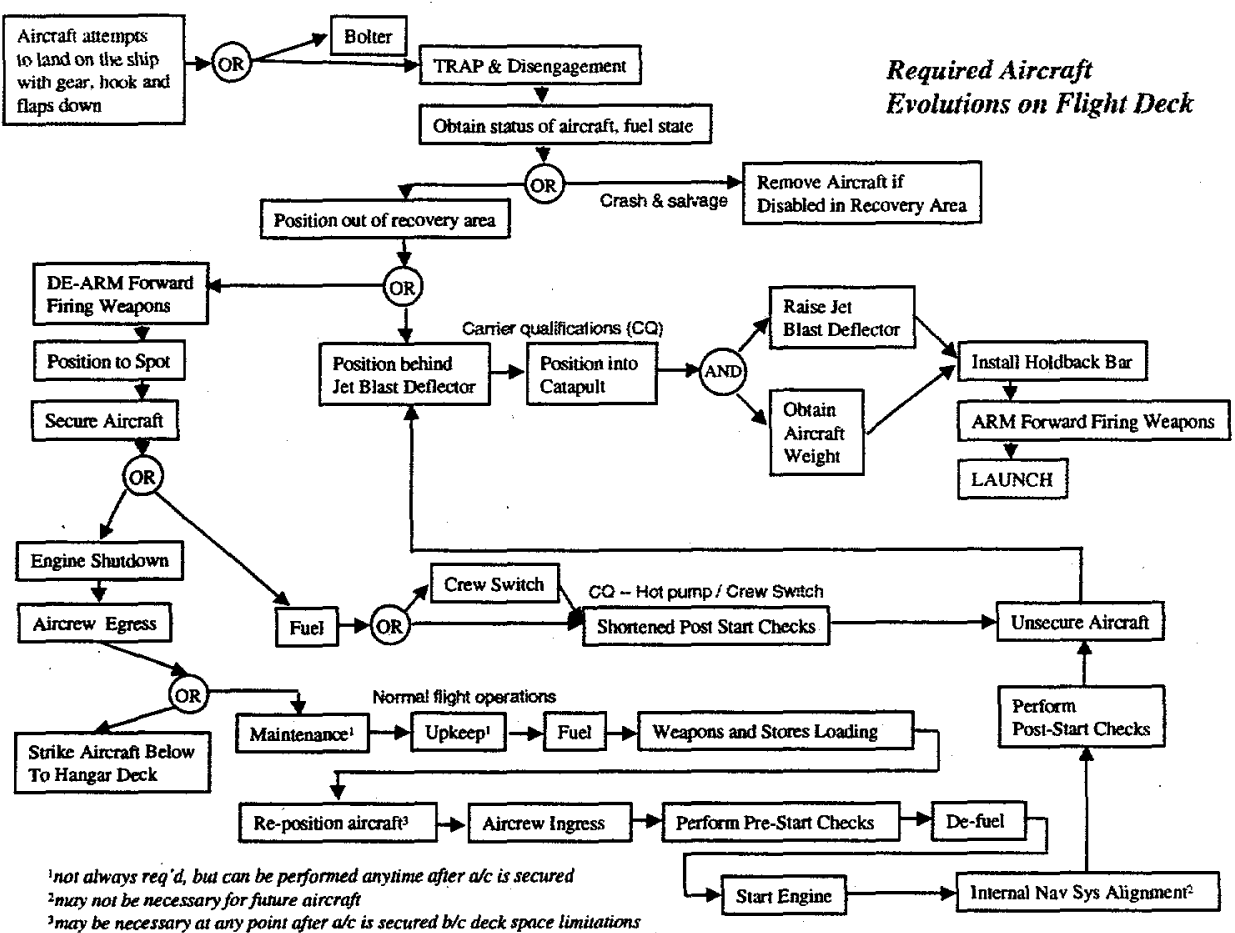

Figure 1. Aircraft servicing flowchart (from USN). 


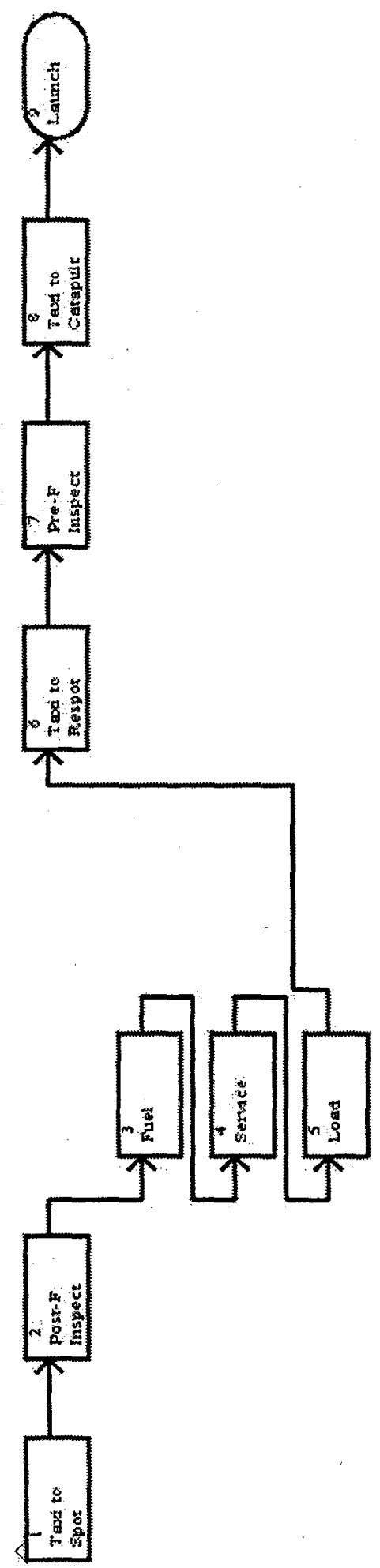

Figure 2. Aircraft servicing high-level network. 


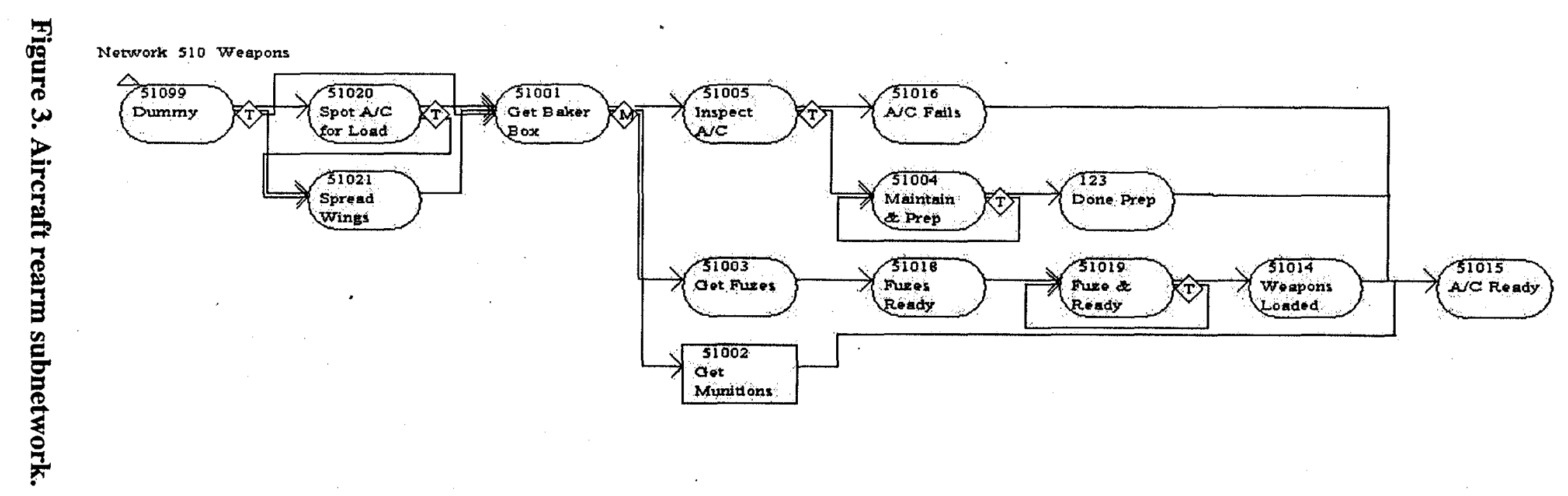




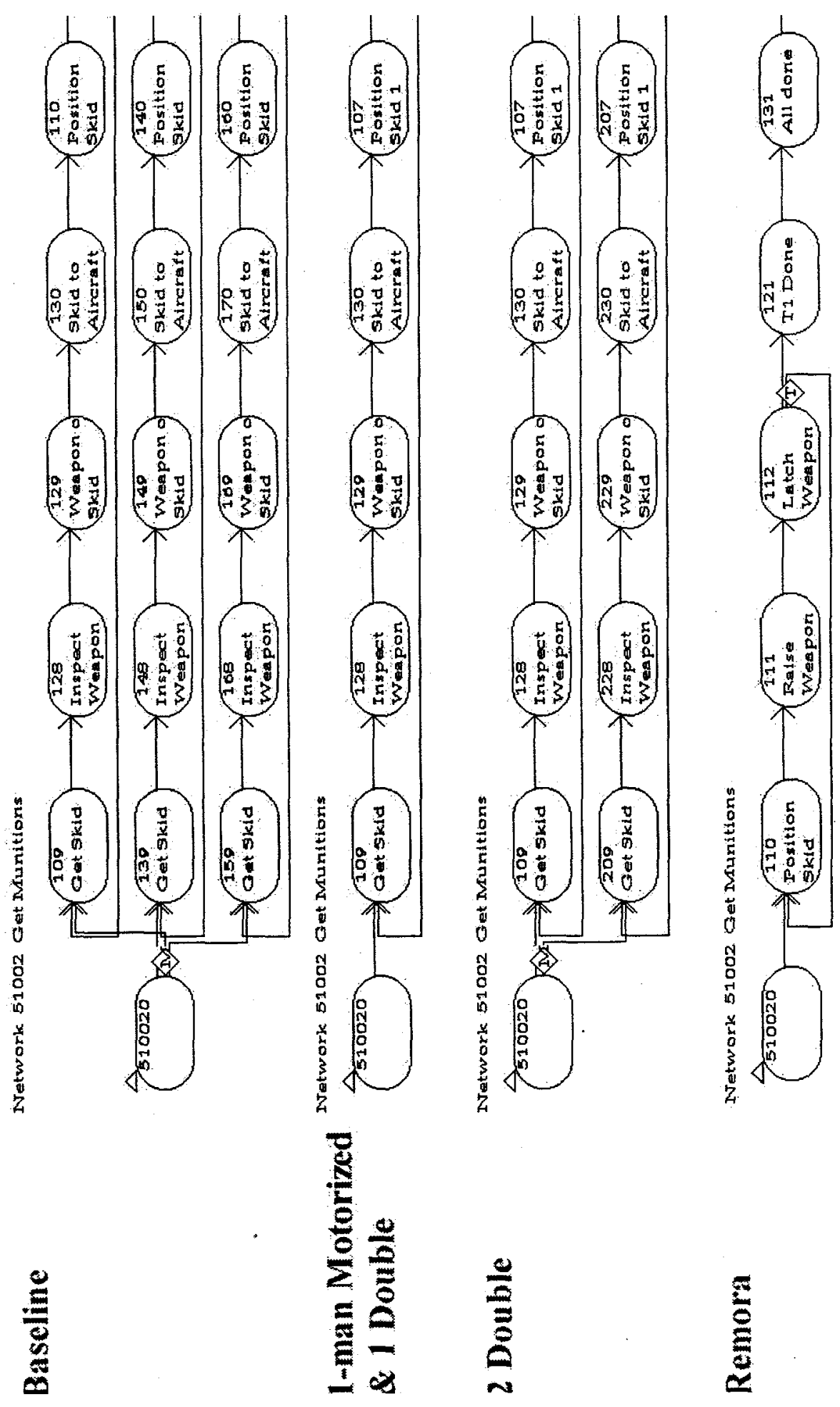

Figure 4. Get munitions subnetwork models. 


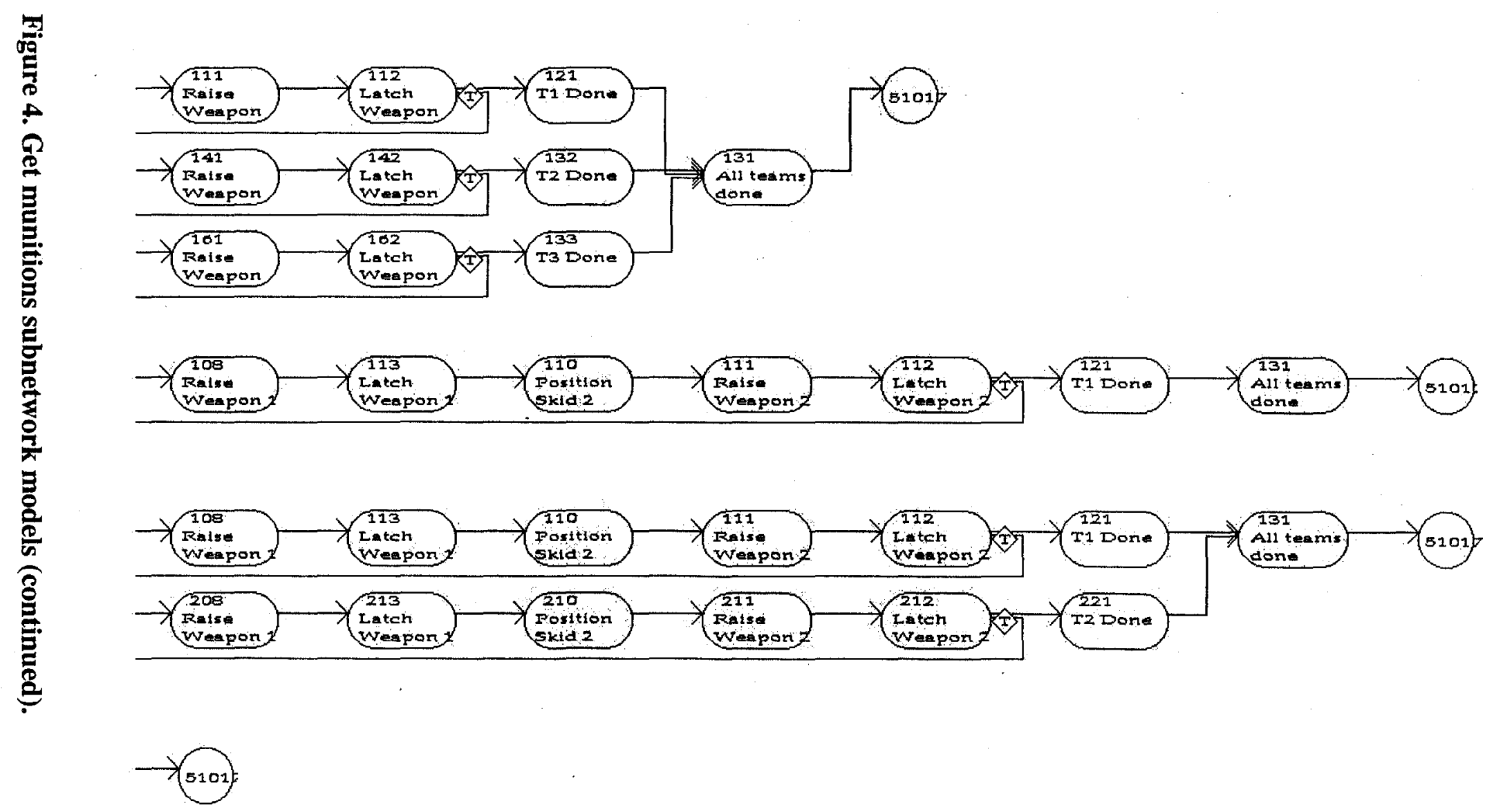




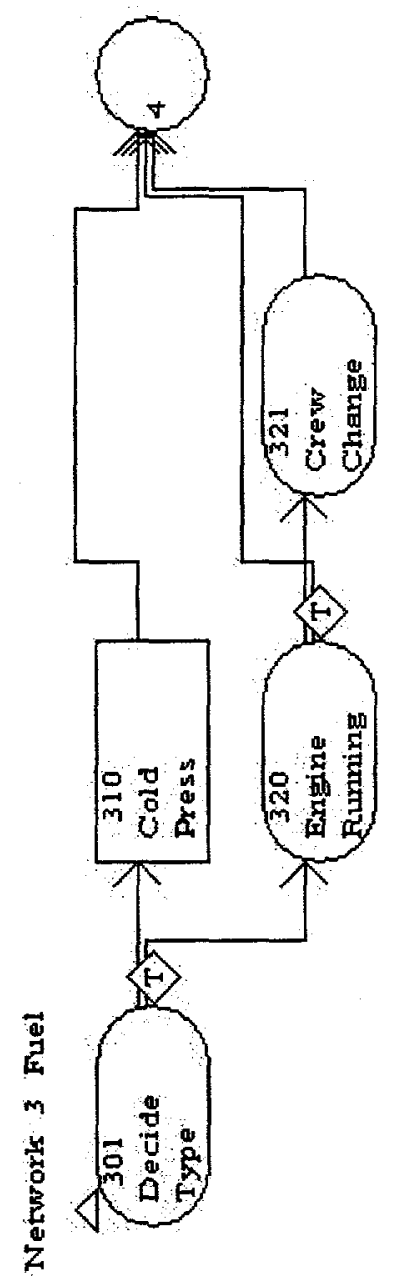

Figure 5. Fuel subnetwork. 


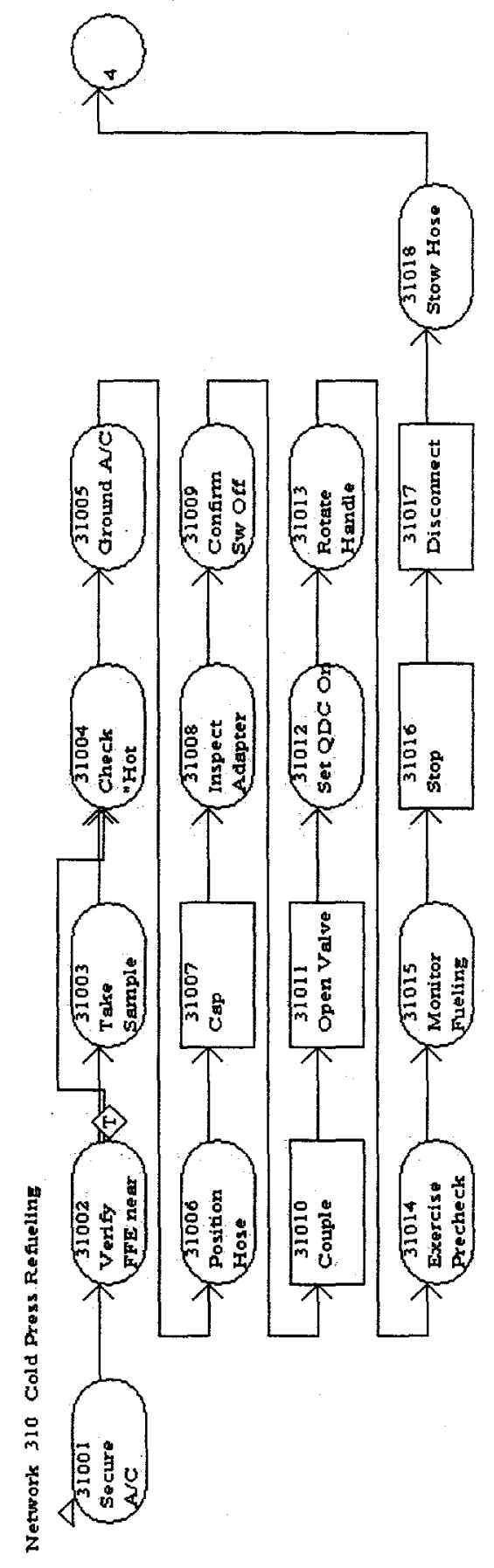

Figure 6. Cold refuel subnetwork (used for baseline, remora, and fast fuel models by modifying appropriate performance parameters within the network). 


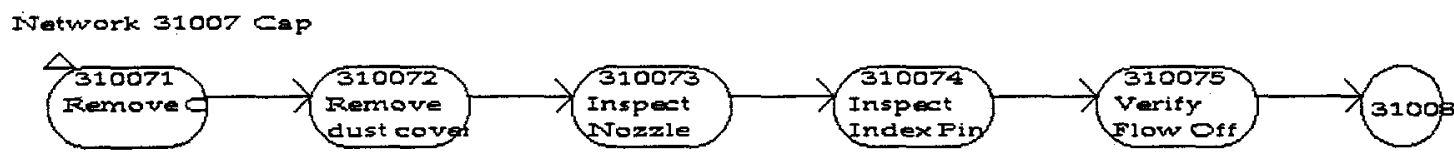

INetwork 31010 Couple

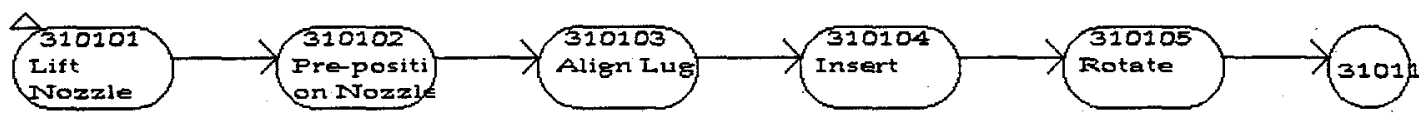

Network 31011 . Open Valve

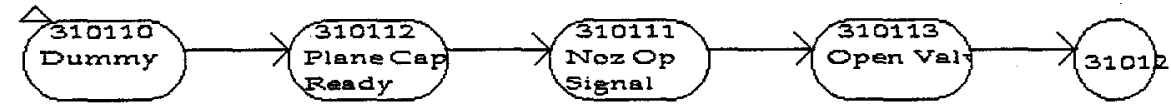

Network 31016 Stop

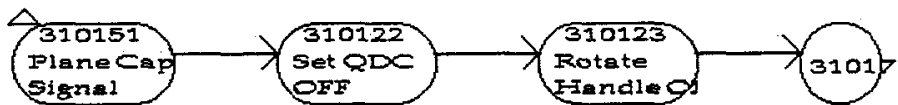

INetwork 31017 Disconnest

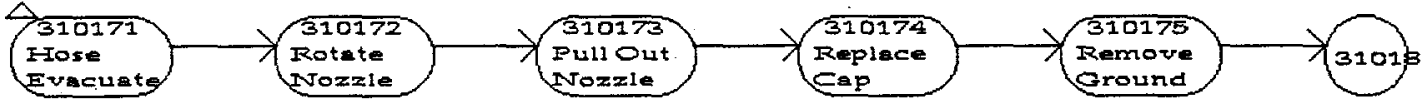

Figure 7. Further fueling subnetworks. 


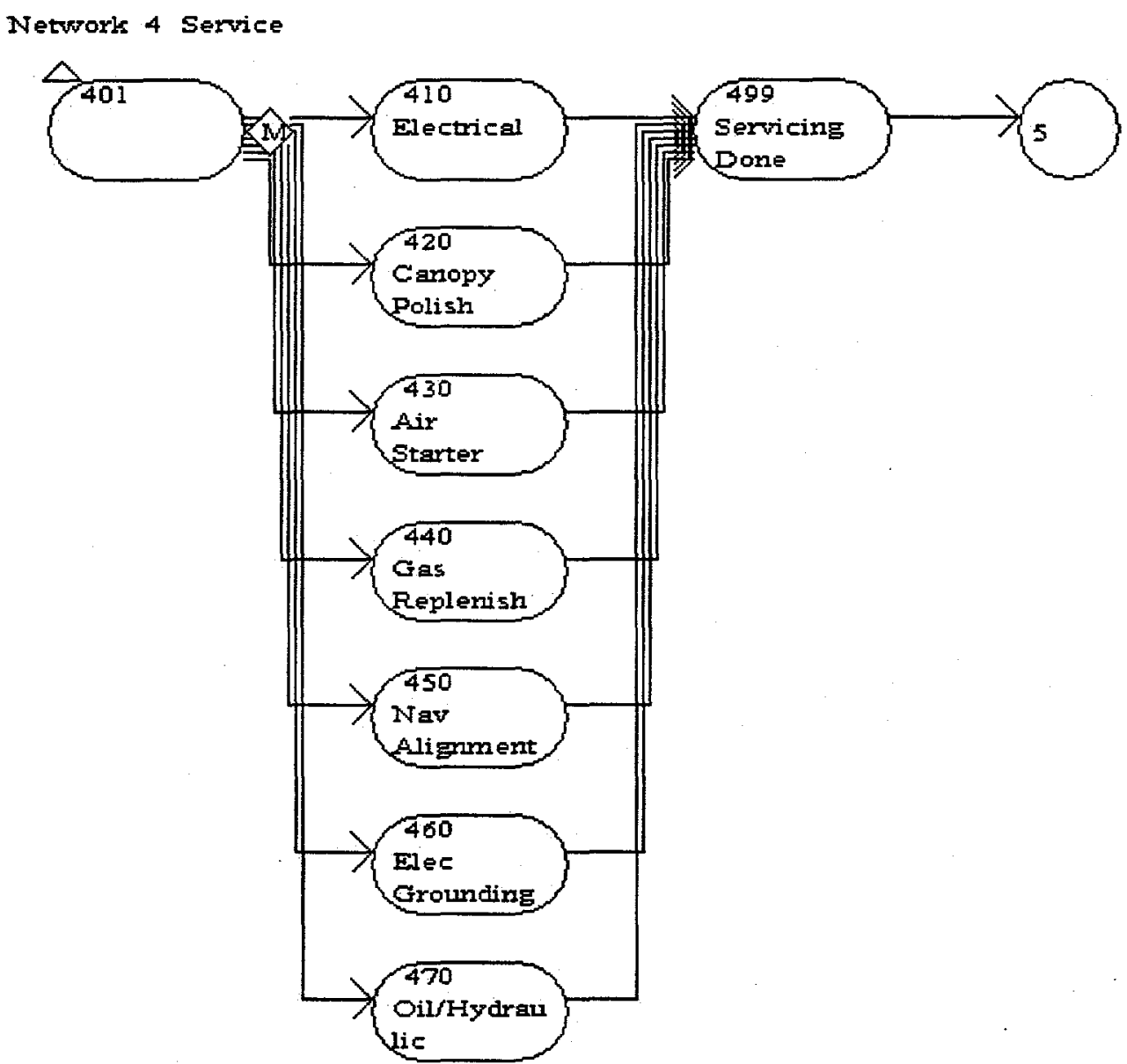

Figure 8. Servicing subnetwork. 



\section{INTERNAL DISTRIBUTION}

1. G. A. Armstrong

2. S. M. Babcock

3. R. E. Barry

4. E. C. Bradley

5. R. D. Bradley

6. T. W. Burgess

7. J. B. Chesser

8-9. D. L. Conner

10. S. D. Curd

11-15. J. V. Draper

16. D. C. Dunning

17. R. L. Glassell

18. V. B. Graves

19. D. C. Haley

20. W. R. Hamel

21-25. J. N. Herndon

26. D. E. Hobson

27-31. J. F. Jansen

32. S. M. Killough

33. D. J. Kington

34. R. L. Kress

35. C. T. Kring

36. J. C. Lewis
37-38. R. F. Lind

39. P. D. Lloyd

40. L. J. Love

41. C. F. Metz, III

42. M. W. Noakes

43-47. F. G. Pin

48. A. H. Primm

49-50. T. L. Ray

51. B. S. Richardson

52-53. J. C. Rowe

54. S. L. Schrock

55. D. H. Thompson

56. H. Toy

57. K. U. Vandergriff

58. V. K. Varma

59. B. S. Weil

60. H. R. Yook

61-62. Laboratory Records

63. Laboratory Records-RC

64. ORNL Patent Section

65. Central Research Library

66. Document Reference Section

\section{EXTERNAL DISTRIBUTION}

67. Warren Baker, Naval Air Warfare Center Aircraft Division, R\&D Office, Code 4.8.1.5, Highway 547, Lakehurst, NJ 08733-5000

68. Fran Carson, Naval Air Warfare Center Aircraft Division, R\&D Office, Code 4.1, Highway 547, Lakehurst, NJ 08733-5000

69. John E. Christian, PEO Carriers, R\&D Director, PMS 378R, Airport Plaza One, $9^{\text {th }}$ Floor, Room 900, 2711 So. Jefferson Davis Hwy., Arlington, VA 22202

70. William Foor, Naval Air Warfare Center Aircraft Division, R\&D Office, Code 4.8.1, Highway 547, Lakehurst, NJ 08733-5000

71-72. Mark Husni, Naval Air Warfare Center Aircraft Division, R\&D Office, Code 4.8.1.3, Highway 547, Lakehurst, NJ 08733-5000

73. Al Kraft, NAVSEA PMS-378, 2531 Jefferson Davis Highway, Arlington, VA 22242-5160

74. Lynne Lebron, Naval Air Warfare Center Aircraft Division, R\&D Office, Code 4.8.1.3, Highway 547, Lakehurst, NJ 08733-5000

75. Gemma M. Meloni, PEO Carriers, S\&T Coordinator, PMS 378R, Airport Plaza One, $9^{\text {th }}$ Floor, Room 900, 2711 So. Jefferson Davis Hwy, Arlington, VA 22202 
76. R. Miller, NAVSEA SEA-03L34, 2531 Jefferson Davis Highway, Arlington, VA $22242-5160$

77. CDR David Odenwelder, NAVSEA PMS-312V, 2531 Jefferson Davis Highway, Arlington, VA 22242-5160

78. Larry Parker, M. Rosenblatt \& Sons, 5700 Thurston Ave., Suite 204, Virginia Beach, VA 23455-3305

79. O. J. Robinson, AIRLANT N85C, 1279 Franklin St., NAS, Norfolk, VA 23511-2494

80. Steve Roman, Naval Air Warfare Center Aircraft Division, R\&D Office, Code 4.8.2, Highway 547, Lakehurst, NJ 08733-5000

81. Anne Sandel, NAVSEA PMS-378, 2531 Jefferson Davis Highway, Arlington, VA $22242-5160$

82. Jeff Tucker, Naval Air Warfare Center Aircraft Division, R\&D Office, Code 4.10.6, Highway 547, Lakehurst, NJ 08733-5000

83. Billy Wright, J. J. McMullen, Inc., 4300 King St., Alexandria, VA 22302

84. Office of Assistant Manager for Energy Research and Development, Oak Ridge Operations Office, Department of Energy, P.O. Box 2008, Oak Ridge, TN 37831-6269

85-86. Office of Scientific and Technical Information, P.O. Box 62, Oak Ridge, TN 37831 